\title{
Reliance on Income Support in Australia: Prevalence and Persistence
}

\author{
Yi-Ping Tseng and Roger Wilkins* \\ Melbourne Institute of Applied Economic and Social Research \\ The University of Melbourne
}

Melbourne Institute Working Paper No. 6/02

ISSN 1328-4991

ISBN 0734015313

May 2002

\begin{abstract}
*This study was undertaken as part of the Social Policy Research Contract with the Australian Commonwealth Department of Family and Community Services (FaCS). Thanks to $\mathrm{FaCS}$ for the provision of data and the financial support that made this research possible, and for comments on earlier drafts. The authors would also especially like to thank Professor Jeff Borland for numerous helpful comments and suggestions. The views expressed in this paper are those of the authors and do not represent the views of the Minister for Family and Community Services, FaCS or the Commonwealth Government.
\end{abstract}

Melbourne Institute of Applied Economic and Social Research The University of Melbourne

Victoria 3010 Australia

Telephone (03) 83443701

Fax (03) 83445630

Email melb-inst@unimelb.edu.au

WWW Address http://www.melbourneinstitute.com 


\begin{abstract}
Welfare dependence or reliance is widely regarded to have adverse consequences for both the community and welfare recipients, yet there have been few studies of the extent and nature of welfare reliance. Indeed, the concept of welfare reliance does not seem to be well defined. In this paper, we attempt to clarify the meaning of the concept and derive reliance measures consistent with this concept. These measures are applied to describe the extent and nature of reliance on income support payments in Australia of persons aged 15-64 years, using Australian Bureau of Statistics income survey data and Australian government administrative data for income support payments. Although the reliance measures available are constrained by the data, a number of insights into reliance on income support in Australia can be obtained. Receipt of income support is characterised by a large number of individuals who are reliant for relatively short periods of time, and a significant number of individuals who become reliant on a long-term, perhaps even permanent basis: one sixth of all recipients aged 15-64 years are continuously on income support for in excess of 51/2 years. Over the course of a year, approximately one third of the Australian population aged 15-64 years is at some stage reliant on income support payments, of whom half are in receipt of income support payments for the entire year. Significant growth in the extent of reliance on income support over the last two decades is evident.
\end{abstract}




\section{Introduction}

The extent of dependence on welfare has been a significant concern for policy-makers in many developed countries in recent decades. Rising welfare dependence is widely regarded to have adverse consequences, for both the community and for welfare recipients. Welfare dependence is associated with significant demands on government budgets and reduced economy-wide market output, and individuals' reliance on welfare is often associated with long-term poverty and social exclusion. Indeed, perceptions of the negative consequences of welfare dependence have been an important motivation for welfare reform in recent years in a number of countries, including the US, the UK and Australia. Despite the policy significance of the issue, research into the extent and nature of reliance on welfare has been limited. To some extent, this may reflect the view that the problem is obvious - too many people on welfare - and therefore little is to be gained by formal study of the issue. This perception, if it exists, is wrong: understanding the incidence and nature of welfare reliance is critical to the design of welfare-related policies. To give an example, the implications of widespread receipt of welfare payments over short intervals of time are quite different to the implications of long-term receipt by a smaller number of individuals.

In this paper we seek to contribute to the body of knowledge on welfare reliance. We begin in Section 2 by attempting to clarify the meaning of the concept "welfare reliance" and then proceed to discuss potential measures of reliance that are consistent with this concept. We conclude that no single measure can adequately describe welfare reliance, but rather several measures need to be employed in order to generate useful insights into the extent, incidence and nature of reliance. We then apply these measures to the study of welfare reliance among the working age population in Australia. Section 3 discusses the available Australian data and the reliance measures that can be employed using this data, while in Sections 4 to 6 reliance estimates for Australia are presented.

The estimates we obtain suggest that up to one third of the Australian population aged 15-64 years is at some stage reliant on income support over the course of a year, deriving, on average, 50 percent of annual income from welfare payments. This represents substantial growth in reliance since 1981-2, when less than one quarter of this age group were at some stage reliant. Significantly, the growth does not appear to result from changes to the observed characteristics of the Australian population; rather, it is the outcome of increased reliance among population groups defined by observed characteristics. Increases in reliance between 1981-2 and 1996-7 are particularly pronounced for males, immigrants and those without post-school qualifications. As might be expected, females have higher rates of receipt and longer average durations on income 
support than males, but strong growth in reliance among males has narrowed the gap between males and females markedly over the last two decades. We furthermore find that, although a large number of individuals are reliant for relatively short periods of time, a significant number are reliant on a long-term, perhaps even permanent basis: one sixth of all recipients are continuously on income support for in excess of $5 \frac{1}{2}$ years. A related finding is that heavy reliance is highly persistent over time. For example, approximately 84 percent of individuals who receive income support payments for over half the year also receive payments for over half of the following year.

\section{Measuring welfare reliance}

While the meaning of "welfare reliance" (or "dependence") is perhaps intuitively clear, it is not a well-defined concept. In an extreme sense, we might think of an individual as reliant over a period of time if the individual's net contribution to the government budget is negative. Such an approach eliminates sensitivity of reliance estimates to the form or labels given to government income and outlays. However, implicit in the common usage of the term welfare reliance is the notion that welfare payments represent the primary income source of recipients, who are not able to meet basic consumption needs with income from other (private) sources. This suggests the study of welfare reliance should focus on those for whom welfare payments represent the primary source of income at the time of receipt, implying a binary concept of individual reliance at a point in time.

With this notion of (instantaneous) individual welfare reliance in hand, it would seem that there are three fundamental questions that a study of welfare reliance should seek to answer: 1) How pervasive is the receipt of welfare? 2) To what extent do individuals rely on welfare payments? and 3) How persistent is individuals' welfare reliance? Ancillary to these questions are issues such as how these features differ across time and population subgroups.

The recipiency rate, defined as the proportion of the population in receipt of welfare payments, estimated at a either a particular point in time or over a given interval of time, will show the extent of receipt of welfare payments. An important issue, which is in fact relevant to all reliance measures, is the definition of receipt that is adopted. Specifically, there are two alternative approaches that might be considered appropriate. The first approach is to simply estimate the proportion of individuals who personally receive welfare payments. This approach is appropriate when the focus is on the demands placed on the government budget by welfare payments. The second approach is to define an individual as being in receipt of welfare if anyone in the income 
unit to which the individual belongs receives welfare payments. An income unit generally comprises either a single person or a couple living together (whether married or not), together with any dependent children. It may be thought of as a group of individuals who obtain their income from the same source(s), in the sense that income obtained by each individual is pooled together to finance the consumption of all members. It follows that, by definition, an individual would be dependent on welfare payments if another member of his or her income unit was in receipt of welfare payments. This approach is therefore likely to provide a more accurate representation of how many individuals depend on welfare payments for basic consumption needs. To provide a concrete example, it would seem preferable to treat as reliant on welfare a dependent child who does not personally receive welfare payments, but whose parents are on welfare.

A distinct issue from the incidence of reliance is the extent of reliance among those who at some stage receive welfare payments. The extent of an individual's reliance over a given period of time can be viewed as the outcome of the interaction between the depth or intensity of reliance at each point in time and the duration of time on welfare. The importance of the intensity dimension is not immediately obvious, since the definition of welfare payments adopted would seem to imply either complete or zero reliance at each point in time. However, the potential for variation in both the number of welfare recipients within each income unit and even the level of private income among such welfare recipients means that examination of this dimension is not trivial. For example, the extent of social exclusion experienced by an individual on welfare may be significantly smaller if limited employment is held by the individual.

The duration dimension may be measured by the total time on welfare payments in a fixed interval of time (TTO) (Gottschalk and Moffitt (1994)). In contrast to many welfare dependence related studies that focus on the length of single spells, we consider that the TTO measure better describes the extent of welfare reliance given the high risk of re-entry into welfare receipt. As noted by Gottschalk and Moffitt (1994), however, the distinction between a single long spell and multiple short spells may be important; but this issue can still be explored by examining the TTO measure in conjunction with the number of spells in the time interval.

A measure that can capture the intensity of reliance is the total percentage of income that derives from welfare payments in a fixed period of time (TPI) (Gottschalk and Moffitt (1994)). Estimation of the TPI at a given point in time provides information on the intensity of reliance at that point in time. The TPI can also be examined over extended periods. For example, if many individuals are heavily reliant on welfare for only a short period of time and then move on to 
well-paid jobs, we may prefer to examine the TPI calculated over a reasonably long period of time in order to identify disadvantaged groups. Against this, if the time interval is too long we may fail to identify individuals' needs at different stages of the life cycle, as well as trends in the TPI distribution over time.

The TTO and TPI measures may also be used to examine the persistence of reliance over time, by examining the relationship between TTO and TPI estimates of individuals in different periods of time (for example, from one year to the next). The two measures can furthermore be combined in various ways to generate information on both the extent and nature of reliance. For example, to focus on the extent of heavy reliance over an interval of time, we might examine the total proportion of time when the point-in-time TPI is greater than 0.8 .

The specific choice of reliance measures will in practice depend on the welfare system in the country under study and, more importantly, data availability. The ideal data set is a long running panel with frequent records on both individuals' welfare income and private income, data that is not often available. In particular, data permitting the estimation of point-in-time TPI's over an extended period is rare, if not non-existent. In the following section, we discuss the measures of welfare reliance based on the recipiency rate, TTO and TPI measures that we apply in the Australian context, given the Australian welfare system and the available data.

\section{Measuring reliance in Australia}

The set of welfare payments in Australia that satisfy the criterion that such payments represent the primary source of income for recipients are collectively known as "income support" (IS) payments. Income support payments are welfare payments made by the Commonwealth government to persons who are assessed as unable to obtain the income necessary to satisfy basic consumption needs from other (private) sources. ${ }^{1}$ Payment levels are set so as to meet basic consumption needs, with the view being that recipients are dependent on those payments as their primary source of income. A second component of the Australian welfare system is the set of "non-income support" (NIS) payments. These payments are intended to supplement the income of persons who obtain most of their income from private sources and largely comprise payments to families with dependent children. NIS payments are not included in the scope of this study,

\footnotetext{
${ }^{1}$ In practice, assessments of the inability to obtain income from private sources are made in the context of community expectations of the behaviour of recipients. For example, "parenting payment single" recipients, unlike Newstart recipients, are not expected to obtain paid employment, even if it is available. Similarly, assessments of "need" for income support depend on a variety of factors, such as the presence of dependent children and the age of the individual.
} 
since such payments do not, on their own, constitute welfare payments as defined for our purposes. $^{2}$

The focus on IS payments is consistent with other studies that have estimated the extent of welfare reliance in Australia in recent years. The Reference Group on Welfare Reform in its Interim Report (2000) examine the extent and nature of reliance among recipients of income support payments using several TTO-based measures, implicitly defining individual reliance at a point in time as "receipt of income support payments at that point in time". ${ }^{3}$ Similarly, both Birrell, Maher and Rapson (1997) and Bond and Whiteford (2001) emphasise the close correspondence between welfare reliance (or dependence) and the receipt of income support payments.

\subsection{The data available}

The data sources available in Australia most suited to the study of reliance on income support payments are the Commonwealth Department of Family and Community Services (FaCS) Longitudinal Data Set (LDS) and the Australian Bureau of Statistics (ABS) Income Distributions Surveys (IDS). ${ }^{4}$

The LDS is a $1 \%$ sample of all individuals who either personally received IS payments, or whose partner received IS payments, at any stage during the period January 1995 to June 2000, drawn from Centrelink administrative records. By virtue of the fortnightly periodicity of the IS payments system, the data set contains information on each individual in the sample for each fortnight in which that individual was in receipt of IS payments over the five and a half year sample period. Information on an individual also appears in fortnights in which the partner of the individual was in receipt of IS payments. The longitudinal nature of the data facilitates examination of the complete payment history of recipients over the sample period, and is therefore particularly suited to study of dynamic aspects of reliance on IS. Payment amounts, payment type and details on a number of individual characteristics are also available, permitting extensive analysis of the features of reliance among those who at some stage received IS payments.

\footnotetext{
${ }^{2}$ However, it should be noted that recipients of IS payments can also receive NIS payments.

${ }^{3}$ The Reference Group on Welfare Reform also report reliance estimates adopting an alternative definition of reliance as "obtaining at least 90 percent of income in the current week from government cash payments". This is a threshold TPI definition of reliance which would in fact define many income support recipients to be not reliant.

${ }^{4}$ The ABS surveys conducted after 1990 are called the "Survey of Income and Housing Costs", but obtain similar information to the earlier Income Distribution Surveys. For the purposes of brevity, in this paper all the surveys are simply referred to as the Income Distribution Surveys.
} 
However, there are important limitations on the aspects of welfare reliance that can be examined using the LDS. The nature of payments-administration data is that no record is generated for an individual in a fortnight in which neither that individual nor his or her partner received IS payments. Furthermore, although private income is recorded in the LDS for those fortnights on payments, it appears to suffer from a high degree of measurement error. ${ }^{5}$ The LDS can therefore only be used for duration-based assessments of the incidence, nature and extent of reliance. ${ }^{6}$ Significantly, it cannot tell us about the intensity of reliance among income support recipients, which is problematic given the potential for large variation in non-welfare income across IS recipients at a point in time, and among IS recipients over time.

Interest in income-based (TPI) measures of reliance provides a motivation for employing the IDS. There are seven income surveys spanning the period 1981-2 to 1997-8, with each collecting income information disaggregated by source, for both the current week and the previous financial year. The IDS therefore permit study of reliance using TPI measures over an extended period of time. The surveys also contain information on individual characteristics, including sex, age, family type, birthplace, educational attainment and labour force status. ${ }^{7}$ The lack of longitudinal information in the IDS does, however, impose important limitations on the measures of reliance that can be calculated. In particular, there is no capacity to consider duration-based measures of reliance, and issues such as the persistence of reliance over time cannot be examined using the IDS. $^{8}$

\footnotetext{
${ }^{5}$ For example (treating a specific fortnight for one individual as a separate observation), 7,788 observations have total private income reported as greater than $\$ 850$ and income support payments reported as positive, unlikely given the applicable income tests. Furthermore, 1,334,225 observations (20 percent of the total sample) have zero income and yet total payments received were less than $\$ 250$, significantly less than the maximum value of the lowest-paying payment. It is unlikely that individuals who have no income received much less than maximum payment. Although there may be some exceptions, 20 percent of total sample seems improbably large.

${ }^{6}$ Additionally, inferences about the extent of reliance in the population as a whole require estimates of population sizes from another data source (such as the ABS Census).

${ }^{7}$ The surveys to 1990 were conducted over approximately two months in the December quarter of the year, while the last four surveys were conducted over a twelve-month period. The sample sizes vary across the surveys, with the number of persons aged 15 to 64 in the surveys equal to $27,755,15,459,26,291,11,820,11,884,12,454$ and 11,796 in each of the respective surveys from 1982 to $1997 / 8$.

${ }^{8}$ Concerns have also been raised about the reliability of the income information in the IDS, particularly for income support payments (for example, Harding and Greenwell (2001)). As in most surveys of this kind, income information is self-reported by respondents, and as such potentially suffers from under-reporting. IS income may be under-reported because of a social stigma associated with IS-receipt, while other income may be under-reported because of privacy and taxation liability concerns; and both may be under-reported because of imperfect recall of income received. This may lead to understatement of the extent of reliance. However, since TPI is a relative measure (of welfare income to total income), under-reporting of income does not necessarily imply reliance estimates will understate the true extent of reliance. Furthermore, if the extent of under-reporting is fairly stable over time, estimates of changes in the extent of reliance are likely to remain valid. The potential does in fact exist to estimate the extent of the problem of under-reporting by comparing inferred population aggregates from the IDS data with income aggregates derived from sources less prone to under-reporting bias. Specifically, administrative data on welfare payments and national accounts statistics may permit us to quantify the extent of under-reporting. Although this is not undertaken in this study, limited insight into the extent of the problem is however provided in Section 4 by the comparison of IS recipiency rates for the IDS with those for the LDS.
} 
The focus of study for both the LDS and IDS is on the extent of reliance on IS payments of individuals who are aged between 15 and 64 years. Thus, the "observational unit" is the individual, as opposed to, for example, the household or family unit. This facilitates study of the incidence and extent of reliance across individuals, implicitly according equal weight to each individual regardless of family or household size, and permitting disaggregation of reliance estimates by subgroups defined according to individual-specific characteristics. However, consistent with the discussion in Section 2, we define an individual's income to be the income from private sources and from welfare that is received by the income unit to which that individual belongs. That is, while the analysis undertaken in this study examines individuals aged 15-64, we examine the extent of reliance of the income unit to which an individual belongs.

\subsection{Reliance measures}

\section{Recipiency rates}

The recipiency rate is defined as the proportion of individuals whose income unit received welfare income in a predetermined period. Recipiency rates are examined using both the LDS and the IDS. Since, for a given interval of time, recipiency rates derived from duration information are equivalent to those derived from income information, this permits limited comparison of the two data sources. For the LDS, recipiency rates are estimated using ABS population data, on the basis that the LDS contains one percent of all income support recipients over the period covered.

\section{Dependency rates (IDS)}

The TPI measure of individual reliance is employed for the IDS:

$$
T P I_{i}^{j}=\frac{W I_{i}^{j}}{W I_{i}^{j}+P I_{i}^{j}}
$$

where $W I_{i}^{j}$ is individual $i$ 's income-unit income from welfare in period $j$ and $P I_{i}^{j}$ is individual i's income-unit income from other sources. Given the information available in the IDS, the length of period $j$ is either one week or one year, and is only available for one week and year for a given individual. The specific statistics based on this TPI measure of individual reliance presented are TPI means and proportions of individuals with TPI's in specified ranges. 
Statistics may be produced for both income in the "current week" (the week prior to the survey interview) and income in the "previous financial year". Estimates for the current week provide information about the average extent of reliance at any given point in time over the period in which the survey took place (two months for the surveys up until 1990, and twelve months for surveys thereafter). Estimates for the financial year, by contrast, tell us the extent of reliance over the whole year. Although weekly and yearly reliance measures are likely to move in the same direction over time, this need not be the case. For example, it is possible for weekly recipiency rates to increase and yearly rates to decrease if the average duration on welfare increases. It is therefore informative to examine reliance estimates over both time frames. However, for the purposes of comparisons over the entire IDS sample period, we focus on measures of annual reliance, since the change from a two-month to a twelve-month sampling period after 1990 means weekly estimates from the first three surveys are not comparable with those from the last four surveys. ${ }^{9}$

Several practical issues arise in the construction of TPI measures, perhaps most fundamental of which concerns the definition of welfare income $\left(W I_{i}^{j}\right)$ that is adopted. Specifically, a decision is required regarding the appropriate treatment of NIS payments, which may be excluded completely from the analysis, included for everyone, or included only for recipients of IS payments. Given the focus on IS recipients, it is arguably preferable to completely exclude NIS payments. However, NIS payments may be important income sources for recipients of IS, and their exclusion would understate reliance, among a group identified to be reliant by receipt of IS payments. This suggests a compromise, in which NIS payments are included for IS-recipients, and excluded for all others.

This treatment of NIS payments does, however, create a problem for annual measures of reliance, which is that, for IS recipients, we cannot simultaneously include NIS payments received when on IS and exclude NIS payments received when not on IS. That is, either all NIS payments received in the whole year by individuals who at some stage were on IS must be included, or they must all be excluded. A bound of sorts can be created by first including NIS payments for those who at some stage were on IS, and then excluding all NIS payments.

\footnotetext{
${ }^{9}$ We define income unit income in the previous year to be the income received in that year by all persons who are currently in the same income unit, even if they were not in the same income unit in that year. It is not possible to obtain information on the actual income unit income in the previous year in the 1982 survey, and the information is also missing for some individuals in other surveys, who presumably were in a different income unit to that at the time of the interview. Individuals with no annual income unit income are dropped from the analysis, since the TPI measure is undefined for these individuals. The numbers of individuals so dropped are 313,204, 283, 181, 175, 136 and 159 for 1982 through to 1997/8 respectively, corresponding to approximately 1 to 1.5 percent of individuals in the sample in each survey. The potential for negative income also creates a problem for TPI measures, which are assumed to lie in the interval $[0,1]$. Those with TPI's less than zero or in excess of one (less than 0.2 percent of individuals) have had the TPI set equal to one.
} 
However, a further complication is that the IDS do not explicitly distinguish between IS and NIS government payments. Rather, information on welfare income is disaggregated by payment type, and there is one payment type category in the last four surveys - "parenting payment" - that comprises both IS and NIS payments. ${ }^{10}$ Thus, despite the focus on IS recipients, the inclusion of all welfare payments for all persons retains some attractiveness because of the problems with respect to the identification and treatment of NIS payments.

In light of the above issues, we therefore present TPI statistics for all three definitions of welfare income. Specifically, the IDS are used to examine reliance on IS payments, reliance on all welfare payments by recipients of IS, and reliance on all welfare payments by all persons. To generate further information on the nature of reliance, reliance estimates are also disaggregated by sex, age, family type, educational attainment, birthplace and payment type for the core approach of including NIS payments for IS-recipients only.

\section{Duration-based measures (LDS)}

The TTO measure of individual reliance is employed as the basis for the reliance statistics presented for the LDS:

$\mathrm{TTO}_{\mathrm{i}}^{\mathrm{j}}=\frac{\sum_{\mathrm{t}=1}^{\mathrm{N}_{\mathrm{j}}^{\mathrm{j}}} f_{i}^{t}}{N_{i}^{j}}$

where $f_{i}^{t}=1$ if individual $i$ 's income unit is in receipt of IS payments in fortnight $t$, and zero otherwise, and $N_{i}^{j}$ is the number of fortnights in period $j$ in which individual $i$ could have been on IS payments, given her age. ${ }^{11}$ Period $j$ could be any length of time within the LDS sample period. For example, if $j=1995$ to 2000 (the entire $5 \frac{1}{2}$ year period), then $N_{i}^{j}=143$ for individuals between the age of 15 and 64 years for the whole period. This TTO measure is bounded between zero and one, telling us the length of time an individual was reliant on IS payments over a given period, as a proportion of the potential maximum time the individual could have been reliant. As a welfare reliance measure, it treats the individual as either "reliant" (in receipt of IS payments) or "not reliant" (not in receipt of IS payments) in any given fortnight.

\footnotetext{
${ }^{10}$ Appendix A provides details on the treatment of payment type categories reported in each of the surveys. Parenting payments have been treated as IS payments for the core analysis, but we conduct sensitivity tests where all parenting payments are treated as NIS payments.

${ }^{11}$ For example, for the entire five and a half year period, a person turning 15 at the start of 1997 would have a maximum total time on income support payments of 3.5 years $\left(N_{i}^{j}=91\right)$.
} 
The longitudinal structure of the LDS also permits examination of the dynamic features of reliance over the sample period. In particular, in addition to measures of the extent of reliance over a given time period, it is possible to study the interdependence between reliance in one period and reliance in other periods. For example, insights into the persistence of reliance over time are generated by examining, for individuals reliant in one period, the extent of reliance in subsequent periods. TTO estimates are also disaggregated by payment type and various personal characteristics.

\section{Income Support recipiency rates}

In this section we present IS recipiency rates, using both the LDS and the IDS, to provide information on the pervasiveness of IS receipt in Australia in recent years. Using the LDS, we focus on annual and average fortnightly recipiency rates for each financial year, in aggregate and disaggregated by sex, age group and payment type. Estimates of the population of Australia at each fortnight are based on linear interpolation between the annual population estimates (ABS (2000)). The motivation for the choice of these sets of recipiency rates is that comparable estimates can be obtained from the IDS. Hence, we present IDS estimates of annual and average weekly recipiency rates for the periods of overlap between the two data sources. This is particularly useful for providing information on the reliability of the IDS.

There are, however, a number of issues in deriving comparable estimates. First, the LDS structure requires us to define an income unit to be either a single person or a couple, excluding dependent children. As such, each dependent child over the age of 15 years is treated as a distinct income unit. This is at odds with the definition of an income unit described earlier (and which is adopted for the TPI estimates which we produce for the IDS). For the purposes of comparisons of the LDS and IDS recipiency rates, the definition of an income unit in the IDS is consequently modified to match the LDS definition. We also restrict attention to 25-64 year olds, since this income unit definition does not produce meaningful results for individuals aged 15-24 years.

A second issue concerns the composition of payments treated as IS payments in the two data sources. The LDS does not contain information on payments to full-time students (Austudy) prior to July 1998; these payments are consequently not treated as IS payments for both the LDS and the IDS. More problematic is that the "parenting payment" category for which the IDS surveys report income comprises both IS and NIS payments. In this study, we treat parenting payment income as an IS payment, implying IDS estimates of IS recipiency rates will be 
overstated. For the purposes of greater comparability, additional estimates are therefore produced for both the LDS and the IDS treating all parenting payments as NIS payments.

The top panel of Table 1 presents annual recipiency rates derived from the LDS for each financial year from 1995-6 to 1999-2000. In 1999-2000, 28 percent of individuals aged 25 to 64 either personally received income support payments, or had a partner who personally received income support payments. Rates of receipt are lower for males than females, and follow a "Ushaped" pattern with respect to age, but for no group (defined by sex and age) is the rate of receipt lower than 20 percent. Changes in the annual incidence of welfare reliance over the fiveyear period are not dramatic, but a systematic decline in recipiency rates has occurred since 1996-7, with the aggregate recipiency rate declining from 29.5 percent. The decreases in reliance have been marginally greater for males, and for both males and females have acted to diminish the strength of the U-shaped relationship between recipiency rates and age. Specifically, the decrease in the recipiency rate is increasing in the absolute distance of the age group from the middle (40-49 years) age group. For example, the percentage point decrease between 1996-7 and 1999-2000 for males, in order from lowest to highest age group, is -3, -1.5, -0.3, -2.7 and -3.

The lower panel of Table 1 contains the corresponding recipiency rates from the IDS for the two financial years of the LDS sample period for which estimates of annual recipiency rates are available. The impact of treating all parenting payments as IS payments is evident, with the aggregate recipiency rate 1.4 percentage points higher for the IDS in 1996-7, and 2.2 percentage points higher in 1995-6. As might be expected from the inclusion of NIS parenting payments, overstatement of IS recipiency rates is greater for females, and indeed restricted to females aged 25-49 years and males aged 30-49 years. For other age groups, the IDS understate the rate of IS receipt. Excluding parenting payments from both the IDS and the LDS, Table B1 in Appendix B provides a clearer picture of the extent of understatement of annual recipiency rates by the IDS. The aggregate recipiency rate is 4.5 percentage points lower for the IDS in 1995-6 and 4 percentage points lower in 1996-7, implying approximately 15 percent of IS recipients are not identified as such by the IDS.

Income support payments are primarily classified (and benefit levels are set) according to the criteria applied for eligibility for receipt. Examination of the extent of reliance on each payment type therefore provides important information on the nature of reliance. For example, the policy implications of growth in the receipt of sole parent pensions are quite different from those associated with growth in the receipt of unemployment-related payments. Table 2 presents annual recipiency rates for each of five IS payment types: unemployment-related payments; 
other (short-term) benefits; parenting payments; sole parent pensions; and other pensions (including disability support pensions and age pensions). The latter three payment types are likely to be associated with longer-term IS receipt compared with the first two payment types. Unemployment payments have the highest (annual) incidence of receipt for males (14\% in 1999$2000)$, followed by other pensions (10.2\%) and parenting payments (6.0\%). For females, by contrast, the highest recipiency rate is for other pensions (14.9 percent in 1999-2000), followed by unemployment payments (10.2\%) and sole parent pensions (7.3\%), suggestive of longer average spell durations for females. Rates of receipt decreased after 1996-7 for all payment types, with the exception of sole parent pensions and, for males, other pensions, for which there were small increases.

The IDS annual recipiency rates by payment type reveal significant under-reporting of IS receipt for most payment types. ${ }^{12}$ Unemployment payments and other benefits, both likely to be received for only a short period of time for many individuals, suffer the greatest under-reporting. This may therefore to a significant extent reflect imperfect recall. ${ }^{13}$ Interestingly, receipt of other pensions is also substantially under-reported for females, something less easily explained by imperfect recall.

The top panel of Table 3 shows, for the LDS, the average fortnightly recipiency rate in each financial year, which we can interpret as the average proportion of the population reliant on welfare at any given point in time. Consistent with intuition, significant drops from annual recipiency rates are evident for the "short-term" payment types, in contrast to the small decreases evident for the "long-term" payments. Unemployment payments and other benefits recipiency rates are roughly 40 percent lower, whereas for the pensions they are only about 10 to 20 percent lower.

Comparisons of LDS fortnightly recipiency rates with the closest IDS analogue available, the weekly recipiency rate, shed further light on the role played by imperfect recall in the underreporting evident for annual recipiency rates. Under-reporting is indeed much less severe for weekly recipiency rates, particularly since weekly recipiency rates must by definition be less

\footnotetext{
${ }^{12}$ It is not possible to determine the extent of under-reporting of receipt of parenting payments, since the proportion receiving only NIS parenting payments is not known.

${ }^{13}$ The survey interview may have been conducted almost two years after the beginning of the period for which respondents were asked to report income.
} 
than fortnightly recipiency rates. IDS estimates of recipiency rates are significantly closer to the LDS estimates, most markedly for unemployment payments and other benefits. ${ }^{14}$

\section{TPI estimates from the IDS}

\subsection{Aggregate Reliance Estimates}

Notwithstanding the evidence of significant under-reporting of IS receipt in the previous financial year, in this section we focus on annual reliance measures. Annual measures are likely to provide a clearer picture of the extent of reliance on welfare and, moreover, unlike weekly measures, are comparable across the entire IDS sample period. In this section, an income unit is defined to comprise immediate family members living in the same household, the target population comprises all persons aged 15-64 years, and education payments (such as Austudy) are included as welfare payments. Table 4 presents various TPI statistics aimed at measuring the aggregate extent of reliance on welfare in Australia. The top panel presents separate recipiency rates for all government welfare payments and for IS payments, which provide a useful starting point for describing trends in the aggregate extent of reliance. In the 1996-7 financial year, approximately 34 percent of individuals were in an income unit at some stage in receipt of IS payments. A substantial increase in the rate of receipt of IS payments over the sample period is evident, occurring entirely after 1989-90: the recipiency rate was 23.2 percent in 1981-2 and 22.3 percent in 1989-90.

Interestingly, although the recipiency rate for IS payments has been increasing since 1990, the rate of receipt of all welfare payments has been declining. In the 1996-7 financial year, as mentioned, over one third of all individuals were in an income unit which received IS payments at some stage during the year, and 47 percent were in an income unit which at some stage received some kind of welfare payment. By contrast, in the 1981-2 financial year, the respective figures were 23 percent and 63 percent. Much of this decline in receipt of all welfare payments in fact appears to have occurred between 1982 and 1990, prior to the increase in the rate of recipiency of IS payments. ${ }^{15}$

\footnotetext{
${ }^{14}$ Significant under-reporting of "other pensions" for females is still apparent, supporting the view that under-reporting for this payment type is unlikely to be due to imperfect recall, and leaving unresolved the source of the under-reporting.

${ }_{15}$ As noted earlier, the treatment of parenting payments as income support payments, when in fact many are NIS payments, will overstate the actual increase in the rate of receipt of income support payments after 1990. Table B2 in Appendix B contains estimates of aggregate reliance for each survey year when parenting payments are treated as NIS payments. These estimates will tend to understate actual reliance on income support payments, because of the exclusion of those parenting payments which are classified as income support, but they are useful for creating a lower bound on reliance estimates. The reliance estimates are in fact somewhat lower in the surveys after 1990, but the broad trends evident in Table 4 are nonetheless still present.
} 
The lower panel of Table 4 headed "Dependency rates" presents mean TPI's among welfare recipients for the three alternative treatments of NIS payments. The proportions of IS recipients in each of four TPI intervals are also reported for the case where NIS payments are included for IS-recipients only. The decline in the recipiency rate for all welfare payments and rise for IS payments suggest a greater concentration of welfare dependence, with fewer individuals in income units receiving welfare, but with those receiving welfare tending to be more heavily reliant on it. Consistent with this intuition, mean annual TPI's among those in receipt of any welfare payments increased from 22 percent to 39 percent. However, reliance among those receiving IS payments has not increased over the sample period as a whole. Although the mean annual TPI from all welfare payments for IS recipients rose from $53 \%$ in $1981-2$ to $61 \%$ in 1994-5, by 1996-7 it was back at 53\%. The increased reliance on welfare among those in receipt of any welfare payments is therefore entirely associated with the increase in the share of welfare recipients who are IS recipients (a more heavily reliant group than NIS-only recipients), and not with any increase in the extent of reliance among IS recipients: in 1981-2, IS-recipients comprised less than 40 percent of welfare recipients, but by 1996-7 comprised over 70 percent of welfare recipients.

The net effect of the increase in the rate of receipt of IS payments and little change in the extent of reliance of IS recipients has been an increase in the extent of reliance in the Australian population as a whole. This is succinctly summarised by the last row of Table 4, which reports the mean annual TPI in the population when NIS payments are included only for recipients of IS payments. This has risen from 12.3 percent in 1981-2 to 17.6 percent in 1996-7.

\subsection{Reliance estimates for population subgroups}

The nature and incidence of reliance is estimated for population subgroups defined by sex, age, family type, birthplace, educational attainment and payment type. Caution should of course be exercised in interpreting the results, since the sources of differences in the extent of reliance between groups, and in the changes experienced over the sample period, may derive from systematic differences in characteristics other than those according to which individuals are grouped. For example, an increase in reliance over the sample period among individuals in a particular education group might reflect changes to the sex, age and family type composition of the education group rather than an effect of being in the education group per se. That is, it may be that, holding constant other characteristics, no increase in reliance among individuals in this education group has in fact occurred. Estimates are presented only for the 1981-2, 1989-90 and 
1996-7 financial years, and only for the case where NIS payments are included only for recipients of IS payments.

\section{Sex and age}

Using a broader definition of an income unit and including individuals aged 15-24 years, recipiency rates presented in Table 5 confirm the finding from the LDS and IDS (Table 1) that the rate of receipt of IS payments is higher for females than males. In the 1996-7 financial year, the female recipiency rate was 5.6 percentage points higher than the male recipiency rate (compared with a difference of 5.3 percentage points for the LDS). Table 5 additionally shows that, not only is the rate of receipt of IS payments higher for females than for males, but so is the rate of dependency among IS-recipients, evidenced by a mean TPI among IS-recipients in 19967 that is 4.2 percentage points higher for females than males. This pattern of greater welfare reliance for females holds across the entire IDS sample period. In fact, the gender gap in reliance was somewhat greater in 1981-2 and 1989-90, with an overall narrowing between 1981-2 and 1996-7 occurring due to relative increases in both the male rate of receipt of IS payments and the extent of reliance among male IS-recipients.

Table 5 also contains IS-recipiency rates and mean TPI's for each of seven age groups.

Consistent with the findings in Section 4, a "U-shaped" pattern for the relationship between the extent of reliance and age is evident. This is most pronounced if the effects of the recipiency rate and the mean TPI among IS recipients are combined by examining the mean TPI in the population, which is given by the product of the recipiency rate and the mean TPI among IS recipients. Significantly, examining the net effect of the recipiency and dependency rates, the trough in the extent of reliance shifted between 1989-90 and 1996-7, from the group aged 30-39 years to the group aged 40-49 years. It also appears that, although after 1989-90 substantial increases in reliance among all age groups occurred, the strength of the relationship between age and reliance weakened, particularly for males (for whom the U-shaped relationship was initially strongest). This derived from greater proportionate increases in reliance among prime age (2549) adults than for the other age groups. ${ }^{16}$

\footnotetext{
${ }^{16}$ The shift in the "trough" from the 30-39 years age group to the 40-49 years age group between 1989-90 and 1996-7 raises the possibility that birth cohort effects exist. Additional analysis by birth cohort (not reported in this paper) provides some indication that the cohort born in the $1950 \mathrm{~s}$, representing the peak of the "baby boom", has a lower propensity to be reliant on IS payments. In both 1989-90 and 1996-7, this cohort had the lowest rates of recipiency and dependency of all the cohorts, and in 1981-2 had among the lowest levels of welfare reliance. However, even for this cohort, significant growth in the extent of reliance is evident after 1989-90.
} 


\section{Family type}

Table 6 presents reliance estimates for each of four family types: single persons, couples with no dependent children, single persons with dependent children and couples with dependent children. Two sets of estimates are presented for 1996-7: one set treating parenting payments as IS payments, the other treating parenting payments as NIS payments.

Of the four family types, single persons with dependent children have by far the highest levels of reliance. This is particularly the case for females, with almost three quarters of female sole parents receiving income support at some stage in the 1996-7 financial year, and with those receiving income support deriving, on average, over 70 percent of income unit income from welfare. Couples, both with and without dependent children, have the lowest levels of reliance. ${ }^{17}$ In terms of changes over the sample period, couples with dependent children experienced the strongest growth in recipiency rates, which more than doubled between 1989-90 and 1996-7. However, a corresponding decrease in mean TPI's among IS-recipients, from approximately 42 to 34 percent, suggests that NIS parenting payments account for much of the apparent increase in reliance among couples with dependent children. Treating parenting payments as NIS payments provides further support for this inference, lowering the recipiency rate for couples with dependent children by approximately 15 percentage points and increasing the mean TPI among IS-recipients by about 14 percentage points. Nonetheless, even though the last two columns of Table 6 exclude those parenting payments that are in fact IS payments, substantial growth in the recipiency rate and mean TPI among IS recipients is still evident for this group.

A pattern not dependent on the treatment of parenting payments is the large increase after 198990 in the extent of reliance for single males with no dependent children. The rate of IS-receipt for this group increased from 24 to 29 percent and the mean TPI among those in receipt of IS payments increased from 57 to 70 percent.

\section{Birthplace}

Reliance estimates disaggregated by immigrant status - specifically, by whether an individual was born in Australia or in another country (Table 7) indicate broadly similar levels of reliance for the two groups in 1981-2. However, a relative increase in immigrant reliance occurred over both the 1981-2 to $1989-90$ and 1989-90 to $1996-7$ sub-periods, such that by 1996-7, mean TPI's

\footnotetext{
${ }^{17}$ For couples with no dependent children, the extent of reliance is higher among females than males because, among those aged 15 to 64 years, many more females than males have a partner over the age of 64 who receives the age pension (and who are excluded from our sample because of age). Treating the age pension as private income eliminates the differences in reliance estimates between males and females in this family type.
} 
for immigrants (equal to the product of the recipiency rate and the mean TPI among ISrecipients) were over 1.25 times those for the native-born for both males and females. An important source of this growth was a relative increase between 1981-2 and 1989-90 in the extent of reliance among immigrants receiving income-support payments. The mean TPI among those in receipt of income-support payments grew from 47.1 to 57.2 percent for immigrant males, compared with an increase from 46.2 to 48.4 percent for native-born males, and for immigrant females grew from 59.3 to 63.9 percent compared with a decrease from 57.6 to 57.3 percent for native-born females.

\section{Educational attainment}

The IDS collect information on highest educational attainment which permits the grouping of individuals into one of three education levels that are consistently defined across all seven surveys: those holding a bachelor's degree or higher, those holding any other post-school qualification and those with no post-school qualifications. Reliance estimates for each of these education groups, presented in Table 8 , show that the extent of reliance is strongly ordered by educational attainment, both in terms of recipiency rates and the extent of reliance among IS recipients. Furthermore, the gap in recipiency rates, particularly between degree-holders and others, has widened substantially over the period. Male degree-holders have had a slight increase in the recipiency rate (from 14.6 to 15.7 percent), and female degree-holders have had a slight decrease (from 5.6 to 5 percent), compared with substantial increases for those with other postschool qualifications (from 15.8 to 27.8 percent for males, and from 20.4 to 32.5 percent for females) and even larger increases for those with no post-school qualifications (from 23.5 to 36.7 percent and 30.3 to 43.1 percent for males and females respectively). The relative decrease in reliance among female degree-holders is especially large, and it is notable that the aggregate extent of reliance among female degree-holders is very similar to that of male degree-holders in 1996-7, in contrast to the higher levels of reliance for other females compared to their male counterparts.

\section{Payment type}

Reliance estimates are produced for six payment type categories. Table 9 presents estimates of reliance on each payment type as well as estimates of the total extent of reliance of individuals classified according to main payment type. The former set of estimates shows the extent of reliance on each payment type, while the latter set show the extent of reliance for groups of 
individuals classified according to a characteristic of the individual - the single largest source of income support payments of the individual's income unit.

Taking into account both recipiency and dependency rates, the most important payment types in all survey years are "unemployment-related" and "other pensions", with "sole parent" pensions also significant for women. ${ }^{18}$ In terms of changes over the period 1981-2 to 1996-7, recipiency rates grew for unemployment, education, parenting and sole parent payments, declined for other allowances, while for other pensions grew substantially for males and contracted for females. Significantly, the extent of reliance on sole parent pensions among female recipients declined substantially, from an average of 63 percent of income in 1981-2 to 40 percent in 1996-7.

Among those in receipt of IS payments, recipients whose main payment type was "other pensions" were the most reliant IS recipients, with the mean TPI among these recipients in 19967 in excess of 75 percent for both males and females. This is likely to reflect, at least partially, the long-term nature of benefit receipt for this payment type. Recipients whose main payment type is "unemployment", "sole parent" or "other allowances" are also highly reliant, with mean TPI's around 50 percent. By contrast, the mean TPI in 1996-7 is less than 36 percent for those in the education category, and less than 25 percent for those in the parenting payment category.

Increases in the extent of reliance over the sample period are evident for males in every payment type category, with mean TPI's increasing by between 7 and 21 percentage points. By contrast, only for unemployment and education payments is a similar pattern evident for females. Reliance among females whose main payment type is the sole parent pension, other pension or other allowance changed little between 1981-2 and 1996-7. Interestingly, however, this implies that the decline in reliance on sole parent pensions among female recipients does not reflect a decline in reliance on income support payments more generally among these recipients, but rather increased reliance on other payment types.

\subsection{Sources of changes in aggregate reliance between 1981-2 and 1996-7}

Sources of changes in the aggregate extent of reliance can be examined by decomposing those changes into the effects of changes in the share of the population in each population subgroup (composition effects) and the effects of changes in the extent of reliance within each subgroup (within-group effects). Focusing on the mean TPI in the population as our measure of the

\footnotetext{
18 "Other pensions" primarily comprises disability support, widow and wife's pensions. The high rate of receipt of parenting payments in 1996-7 gives a misleading impression of their importance. Mean TPI's among parenting payment recipients were approximately 12 percent, compared with approximately 60 percent for other pensions and 40 percent for unemployment payments. This probably reflects the impact of NIS parenting payments.
} 
aggregate extent of reliance, we can isolate the distinct contributions of these two sources of change using the following decomposition of the change in the mean TPI between 1981-2 and 1996-7:

$$
R^{97}-R^{82}=\underbrace{\left(\sum_{j=1}^{J} S_{j}^{97} R_{j}^{97}-\sum_{j=1}^{J} S_{j}^{97} R_{j}^{82}\right)}_{\text {within-group effect }}+\underbrace{\left(\sum_{j=1}^{J} S_{j}^{97} R_{j}^{82}-\sum_{j=1}^{J} S_{j}^{82} R_{j}^{82}\right)}_{\text {composition effect }}
$$

where $S_{j}^{y}$ is the share of the population in group $j$ in year $y$ and $R_{j}^{y}$ is the mean TPI in group $j$ in year $y$ and where each individual the population is classified into one of $J$ groups. Equation (1) evaluates the within-group effects at 1996-7 group shares and the composition effects at 1981-2 group TPI's. Alternatively, we can evaluate within-group effects at 1981-2 shares and composition effects at 1996-7 TPI's by replacing the second and third terms of the right-hand side of Equation (1) with the term $\sum_{j=1}^{J} S_{j}^{82} R_{j}^{97}$.

Table 10 presents decomposition results for four alternative groupings of the population:

- family type (16 groups: male/female; single/couple; zero/one/two/three or more dependent children)

- birthplace (4 groups: male/female; native-born/foreign-born)

- educational attainment (6 groups: male/female; bachelor's degree or higher/other post-school qualification/no post-school qualifications)

- age (14 groups: male/female; 15-19/20-24/25-29/30-39/40-49/50-59/60-64 years of age)

The results indicate that changes in the family type, birthplace, educational attainment and age composition of the population do not explain the increase in the aggregate extent of reliance in the population. Indeed, changes to the educational attainment and age composition have acted to decrease reliance. It is therefore the changes within groups that have been documented in Section 5.2 that account for the aggregate increase.

\section{TTO estimates from the LDS}

As discussed, the primary value of the LDS is its ability to provide information about the dynamic properties of reliance. The population of analysis is all individuals who were at some 
stage in the period January 1995 to June 2000 in an income unit that received income support payments while they were aged between 15 and 64 years. ${ }^{19}$

The analysis comprises four parts. First, examination of the total extent of reliance is undertaken by studying the TTO distribution for the entire 51/2-year period (1995-2000). The distribution of TTO is also examined separately for each payment type to provide further insights into the nature of welfare reliance. Second, the distribution of TTO by individual and family characteristics is investigated to explore the types of individuals more likely to become heavily welfare reliant. In the third subsection, TTO distributions over a one-year time frame are examined in order to provide information on the extent of reliance over a shorter period of time and the changes in TTO distributions which have occurred over the sample period. To study the nature and extent of the persistence of welfare reliance over time, reliance "transition" tables are presented in the fourth part of the LDS analysis. These tables provide information on the relationship between the extent of reliance in one year and the extent of reliance in other years.

\subsection{The TTO Distribution 1995-2000}

\section{Distribution of the proportion of time on income support (TTO)}

Figure 1 presents histograms of the distributions of the proportion of time that each individual was in an income unit which was in receipt of IS payments (i.e., TTO distributions). The top panel shows, for the entire sample period, the TTO distribution for all persons aged 15-64. The graph shows TTO has a U-shaped distribution, with the density decreasing and then increasing as TTO become larger. There is a large spike for TTO around 1, and to be precise, 16.6 percent of our sample fully relies on IS (TTO $=1)$ for the entire observation period. Comparing males and females, in the lower two panels of Figure 1 we see a tendency towards higher TTO's for females. The spike at the $0.98-1$ TTO interval is approximately 50 percent higher for females than males, while a considerably higher proportion of males have TTO's below 0.3 .

\section{Distribution of TTO by payment type}

Figure 2 shows the distribution of the proportion of time on each of six payment types: unemployment benefits, other allowances, parenting payments, sole parent pensions, age

\footnotetext{
${ }^{19}$ Sensitivity analysis is also undertaken for some of the analysis by examining the restricted group aged 20-55 years. The motivation for excluding those aged 15-19 years is that persons in this age group are often dependents (or treated as dependents by the income support system). The 55-64 age group is excluded to attempt to remove the effects of the age pension: women over 60 years of age are eligible for the age pension, and those who were over 55 years of age in 1995 would turn 60 in 2000.
} 
pensions, and other pensions. ${ }^{20}$ For example, the sample for the top left panel (unemployment benefits) comprises all individuals on unemployment benefits at any stage over the full sample period, and the TTO measure is the total proportion of time on unemployment benefits. The proportion of all IS-recipients in each sub-sample are listed at the bottom of the respective figures. The group receiving unemployment benefits is the largest, with 67 percent of individuals receiving IS payments over the sample period at some stage observed on this payment type. An individual can be in more than one category because it is possible for an income unit to receive payments for multiple payment types (at different points in time, or even at the same point in time), and it is possible for an individual to change income units over time.

As might be expected, TTO's tend to be higher for pensions. For example, in excess of 40 percent of age pension recipients have a TTO from that payment type equal to one. TTO's for unemployment benefits, by contrast, are for the most part concentrated at less than 0.3 in the TTO distribution, with only about 2 percent of recipients reliant on unemployment benefits for the whole period.

\subsection{TTO by individual characteristics}

In this section, we examine TTO estimates by individuals' sex, birth cohort, birthplace, ethnic group, family type and number of spells on payments in the entire period. For each population subgroup, we examine the mean TTO as well as the proportion of individuals in each of four TTO intervals: "low" (0-0.24), "medium" (0.25-0.74), "high" (0.75-0.99) and "maximum" (1). The exception to this approach is for TTO distributions by family type, which require an alternative approach because an individual's family type is potentially time-varying and is not known when the individual is not on IS. We therefore report the average proportion of time that individuals belong to a certain type of family for persons in different TTO intervals. For example, for individuals with TTO's less than 0.25 , we report the average proportion of time they were married with dependent children while they were on income support.

\section{Sex and birth cohort (age in January 1995)}

Table 11 presents TTO estimates for the full 51/2 year sample period, disaggregated by sex and age (in January 1995). Consistent with the TTO histograms presented in Figure 1, it is evident that male IS-recipients tend to have a lower proportion of time on income support than female IS-recipients. The mean TTO for males is approximately 15 percent lower than for females, and

\footnotetext{
${ }^{20}$ The details of payment type classification are provided in Appendix A. Although we focus on individuals less than 65 years of age, as noted earlier, an individual aged 15-64 may still be reliant on the age pension.
} 
particularly significant is that 19.8 percent of female recipients spent the entire period on IS, compared with 13.4 percent of male recipients. Since our definition of TTO is the total proportion of time on IS for the income unit, the differences between males and females will derive from differences between single men and single women, as well as the greater number of females than males aged under 64 years who have partners over the age of 64 years who are in receipt of IS.

TTO estimates by age indicate that, for both males and females, reliance among IS-recipients is increasing in age. Approximately three quarters of the cohort aged 10-14 in January 1995 who are in our sample have a TTO less than 0.25 , while no-one in this group is reliant on IS payments for the entire observation period. By contrast, the oldest cohort (aged 55-64 years in January 1995) has only 13 percent of male recipients and 8 percent of female recipients with TTO's less than 0.25 , and 45 percent of males and 56 percent of females have a TTO equal to one. Note that, although the middle age groups have higher TTO's than younger age groups, it does not follow that individuals in this age group are more heavily reliant on IS payments. Recipiency rates for each age group reported in Table 1 showed the rate of receipt to in fact be lowest for those aged 30-49 years. Thus, individuals in middle age groups are less likely to have received any IS payments during the $5 \frac{1}{2}$-year period, but those who did receive IS did so for a larger proportion of time than was the case for younger age groups.

\section{Birthplace and ethnic group}

Immigrants might be expected to exhibit higher welfare reliance due to such factors as comparative disadvantage in the labour market (for example, deriving from lower English language ability). We therefore might expect a tendency to longer durations of receipt of IS for foreign-born individuals, an expectation borne out by the TTO estimates presented in Table 12. About 44 percent of native-born males in the sample have a TTO less than 0.25 , compared with 38 percent for foreign-born males. Similarly, the corresponding figures for females are 37 percent for natives and 29 percent for immigrants. For both males and females, the lower proportion of foreign-born recipients with TTO's below 0.2 is almost entirely accounted for by the higher proportion with TTO's greater than 0.75 , there being little difference in the proportion with TTO's in the intermediate $(0.25-0.74)$ TTO range.

Table 12 also compares the TTO distribution of Aboriginal and Torres Strait Islander (ATSI) persons with others. The proportion of individuals with a "low" TTO is significantly smaller for ATSI recipients than other recipients - 12 percentage points lower for males and 19 percentage 
points lower for females. ATSI individuals have a much larger proportion of recipients with a TTO between 0.25 and 0.99 , but, interestingly, a smaller proportion with a TTO equal to one.

\section{Number of spells}

Table 13 reports TTO statistics for individuals classified according to number of spells on income support over the LDS sample period. About 65 percent of our sample have only a single benefit spell in the 51/2 years, and they are likely to have either a very high or a very low TTO. "Churners" (those who move into and out of IS-receipt), by contrast, are more likely to have an intermediate TTO, an intuitive result given the breaks from payments implied by multiple spells over the sample period. For example, approximately 80 percent of individuals with five or more benefit spells have a TTO between 0.25 and 0.74 . Consistent with this finding, the bottom row of Table 13 shows that the average number of spells increases and then decreases as TTO become larger, peaking in the $0.25-0.74$ TTO interval. This indicates that neither spell length (a commonly used reliance measure), nor the number of spells on benefits, are ideal measures of the extent of welfare reliance.

\section{Family type}

Since family circumstances may change over time, we are not able to present TTO distributions by marital status and whether dependent children are present or not. Instead, we present, for each TTO interval, the average proportion of time individuals were in each family type when they were on IS. For example, the last column of Table 14 shows that females who were on IS for the entire $5 \frac{1}{2}$ years were on average single with dependent children for 15 percent of the period they were on IS (i.e. the whole period) and single without dependent children for 33 percent of the period. The nature of the table is such that it is not meaningful to compare the numbers vertically, since there are substantial differences in the population shares of the family types. Instead, "horizontal" comparisons should be made in order to obtain insights into the relationship between family type and reliance. For example, of those females with a TTO in the range 0-0.24, on average 15 percent of the time on IS was in a single parent family, while for females with a TTO in the range $0.75-0.99$, on average 29 percent of the time on IS was in a single parent family.

Comparing the numbers in this manner, it is evident that the proportion of females who are single with dependent children is increasing in TTO up to the "high" level. This supports the hypothesis that sole parent females are more likely to heavily rely on IS. For both males and 
females, the average proportion of time individuals were in a couple with dependent children is similar across the different TTO groups, with the exception of those with a TTO equal to one, who have a significantly smaller average proportion of time in this family type. Males and females in this "maximum" TTO group have a much higher proportion of the time being in couples without dependent children than the other TTO groups. This may be due to persons over 55 years of age, who are unlikely to have dependent children and among whom a large proportion have a TTO greater than 0.8 . In order to abstract from this age effect, we present the same table for persons aged 20-55 years in Appendix B. From Table B3, we can see that the proportion of time being in a couple without dependent children for people with a TTO equal to one is in fact much lower than in Table 15, although for females it is still somewhat higher than for the other TTO groups.

In the bottom panel of Table 14, the mean proportion of time individuals were single, were in a couple with both partners on IS, and were in a couple with only one partner on IS, is presented for individuals in each TTO interval. The mean proportion of time individuals were in a couple with both adults on IS is higher for the high TTO ranges than is the case for the low TTO ranges. By contrast, the proportion of time individuals were single or part of a couple with only one adult on IS is lower for the high TTO ranges. This suggests that for income units with two adults on IS it is more difficult to exit benefits, which perhaps reflects the effects of a high replacement rate of IS payments for these individuals. However, it is also possible that members of such couples have similar characteristics and consequently, for an individual who is likely to rely on IS, the partner is also more likely to rely on IS.

\subsection{Changes in TTO over time}

To examine changes to the extent of reliance over the LDS sample period, Table 15 presents TTO statistics for the shorter time frame of one year. The population for each respective year is "individuals who received IS payments at some stage in that year". ${ }^{21}$ As might be expected, given the reduced potential for changes to circumstances leading to exit from IS-receipt, the mean TTO within one year is much higher than the mean TTO over $5 \frac{1}{2}$ years. The average oneyear TTO is about 0.75 , compared with the $5 \frac{1}{2} 2$-year TTO of 0.44 for males and 0.53 for females.

\footnotetext{
${ }^{21}$ The one-year TTO is not available for 2000 because the sample period ends in June 2000. The 6-month TTO is not presented for 2000 because it is not comparable to the one-year TTO results.
} 
The number of individuals receiving IS over the course of the year is fairly stable across the five year period to 1999 , at about 36,000 (translating to a population figure of 3.6 million) in each year except 1995 , in which only slightly fewer $(34,500)$ were on IS. The average TTO is also slightly smaller for 1995, with a smaller proportion of individuals on IS for the entire year compared with the other years. Significantly, the proportion of the sample with a TTO equal to one increases over the five-year period, with the proportion in each year higher than in the preceding year, rising from 41 percent in 1995 to 53 percent in 1999. Further analysis (see Appendix C) shows that the proportion of individuals who at some stage in the year received unemployment payments or other allowances, both of which are regarded as "short-term" benefits, has decreased over the LDS sample period, while the proportion of individuals who at some stage in the year received a sole parent pension or "other" pension has increased. This implies that the increase in welfare reliance among recipients could derive from changes in the payment type composition of recipients rather than changes in the proportion of time on each payment type, although we do not formally investigate the role played by such compositional changes in this paper.

\subsection{Transitions between different levels of reliance}

In order to further understand the extent and nature of the persistence of welfare reliance, we explore the movement of individuals between TTO categories over time. Specifically, we examine the proportion of individuals who move between different TTO categories in two consecutive years for 1-year TTO measures. We furthermore focus attention on individuals classified as heavily reliant in a given year, defined as having a TTO in excess of 0.5 , examining the probability of an individual being heavily reliant and not reliant $(\mathrm{TTO}=0)$ in subsequent years.

\section{Movement between TTO groups in two consecutive periods}

Table 16 presents individuals' transitions between different TTO ranges in two consecutive years, 1998 and $1999 .{ }^{22}$ For example, the cell at the second row, first column of Table 16 shows that 6.2 percent of individuals had a TTO which was positive but less than 0.25 in 1998 and were not on IS in 1999. The cell at the first row, first column is zero because our sample comprises only those observed on IS at some stage during 1998 or 1999. Individuals with a smaller TTO in 1998 were more likely to completely exit IS payments in 1999, while those who were heavily

\footnotetext{
${ }^{22}$ Results have also been obtained for TTO movements between all other year-pairs, but are not reported. All year-pairs exhibit similar patterns in TTO movements, with the exception that the proportion of the sample with a TTO equal to one in both years is increasing over time.
} 
reliant in 1998 were more likely to be heavily reliant in 1999 also. Thirty-seven percent of recipients in the two years have a TTO equal to one in both years. Those who were on IS at some stage in 1998 were more likely to become fully reliant on IS in 1999 than those who were not. However, it should be noted that the latter group includes people whose spells straddle the two years. For example, it doesn't necessarily follow that those who early in 1998 went on payments briefly are more likely to be fully reliant in 1999 than those who didn't go on income support at all in 1998. The increased chance of being fully reliant in 1999 may simply derive from individuals who happened to start spells in 1998 that were still going at the end of 1999.

\section{Heavily reliant persons}

The top panel of Table 17 presents, for those who are heavily reliant on IS in a given year (defined by TTO $>0.5$ ), the probability of being heavy reliant in subsequent years. For example, the cell in the first row and second column indicates that 84 percent of those individuals with a TTO greater than 0.5 in 1995 remained heavily reliant on IS in 1996. Especially striking is that 71 percent of individuals who were heavily reliant on IS in 1995 were still heavily reliant four years later. Comparison of the numbers on the same diagonal (downward and to the right) also indicates that the persistence of reliance on IS did not change much over the sample period. For example, the proportion of heavily reliant persons who were also heavily reliant in the following year is approximately 84 percent for all year-pairs.

The lower panel of Table 17 presents the proportion of heavily reliant people who completely exit payments in subsequent years. We can see that 6 percent of people who were heavily reliant in 1995 were not on IS in 1996. As might be expected, this percentage increases as the time difference becomes larger: by 1999, 22 percent of those who were heavily welfare reliant in 1995 were not on IS. However, this implies that 78 percent of heavily reliant people in 1995 were still reliant on IS to some extent in 1999, which is further evidence that reliance on income support is highly persistent over time.

\section{Conclusion}

The most recently available evidence from the IDS (the 1996-7 financial year) indicates that roughly thirty percent of the Australian population aged 15 to 64 years is reliant on income support at some stage of the year. This implies significant growth in the extent of reliance on income support has occurred since 1981-2, when less than one quarter of the population aged 15 to 64 years received income support payments, and when the extent of reliance among recipients 
was similar to that in 1996-7. Most of the increase appears to have occurred after 1989-90, and has been most pronounced among single males, particularly those born outside Australia and those with no post-school educational qualifications. However, growth has also occurred, to a lesser extent, for females, among whom the extent of reliance on income support still exceeds that of males in 1996-7.

The LDS, which comprises complete payment histories of $1 \%$ of all individuals ever to receive income support payments in Australia between January 1995 and June 2000, provides some indication of a decrease in the rate of IS-receipt after 1996-7, but not of a magnitude to offset the much larger rise between 1989-90 and 1996-7. The LDS also shows the distribution of time in receipt of IS payments to be "U-shaped", with TTO's most heavily concentrated below 0.2 and above 0.9 . Thus, while a significant number of people temporarily depend on IS payments, a large number also become reliant on IS payments on a long-term basis. As might be expected, long-term IS receipt is primarily associated with pensions, and over the LDS sample period there has been some increase in the proportion of IS recipients in receipt of pensions. Thus, while the rate of receipt of IS payments declined slightly after 1996-7, it does not appear that the aggregate extent of reliance on IS payments has in fact declined over the LDS sample period.

A valuable extension of the descriptive analysis presented in this paper would be formal analysis of the determinants of the extent of reliance on income support. Specifically, estimation of a model of the dependence of welfare reliance on characteristics would permit us to quantify the role of specific factors in determining the extent of individual reliance. Such a formal approach to the study of the determinants of reliance would also be useful for analysis of the determinants of changes in reliance (in both extent and nature) over time, and in particular decomposing changes to patterns of reliance over time into those due to characteristics changes (including private income changes) versus those due to changes in other factors such as government policy.

Although the IDS and LDS are able to provide us with important insights into the extent and nature of reliance on income support in Australia, they do suffer from significant limitations. Possibly the greatest weakness of the available data is that we do not have detailed income information on a longitudinal basis. The IDS contain the income information, but not on a longitudinal basis, while the LDS contains longitudinal information over a reasonably long period, but not the income information. A data set combining both features would be a welcome development for the study of welfare reliance in Australia. 


\section{References}

Australian Bureau of Statistics (ABS) (2000) Population by Age and Sex, Australia, Catalogue No. 3235.0.55.001, Canberra.

Birrell, B., C. Maher and V. Rapson (1997) "Welfare Dependence in Australia," People and Place, Vol. 5, No. 3, 44-53.

Bond, K. and P. Whiteford (2001) Trends in the Rates of Receipt of Income Support and Employment Outcomes Among People of Workforce Age: Australia 1965 to 1999, unpublished working paper.

Department of Family and Community Services (FaCS) (2000) Interim Report of the Reference Group on Welfare Reform, FaCS, Canberra.

Gottschalk, P. and R. Moffitt (1994) “Welfare Dependence: Concepts, Measures, and Trends,” American Economic Association Papers and Proceedings, Vol. 84, No. 2, 38-42.

Harding, A. and H. Greenwell (2001) "Trends in Income and Expenditure Inequality in the 1980s and 1990s," Paper presented to the $30^{\text {th }}$ Annual Conference of Economists, 24 September 2001 .

U.S. Department of Health and Human Services (2000) Annual Report to Congress

Whiteford, P. (2000) The Australian System of Social Protection - An Overview," Policy Research Paper No. 1, Department of Family and Community Services. 
Table 1: IS recipiency rates (annual) - Persons aged 25-64 (\%)

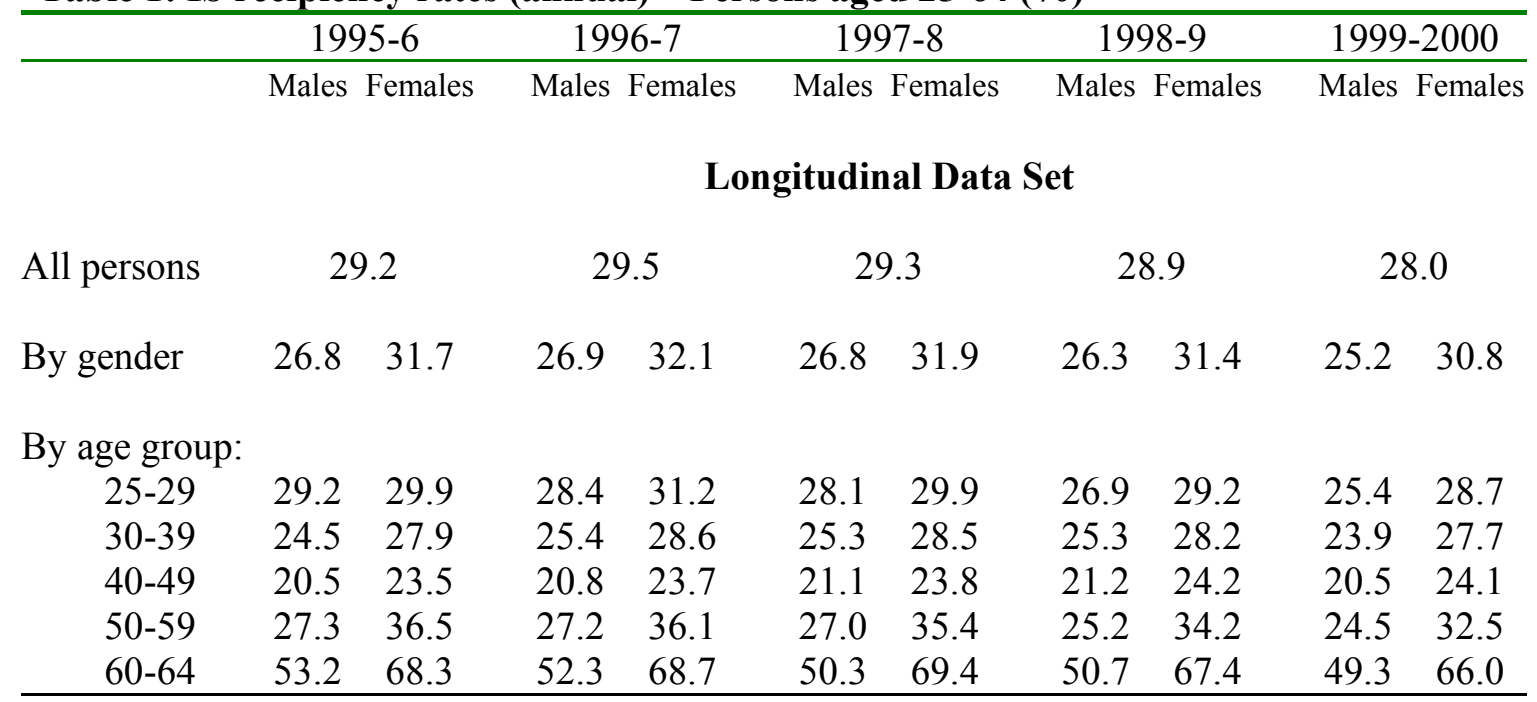

\section{Income Distribution Surveys}

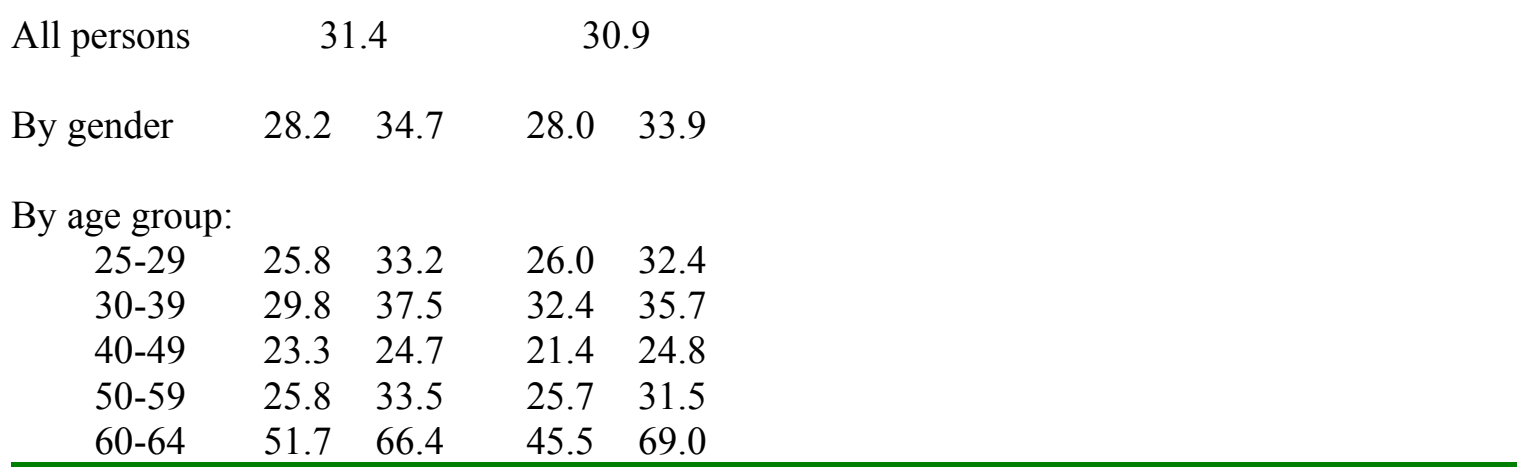


Table 2: IS recipiency rates by payment type (annual) - Persons aged 25-64 (\%)

\begin{tabular}{ccccc}
\hline $1995-6$ & $1996-7$ & $1997-8$ & $1998-9$ & $1999-2000$ \\
\hline Males Females & Males Females & Males Females & Males Females & Males Females
\end{tabular}

\section{Longitudinal Data Set}

$\begin{array}{lcccccccccc}\text { Unemployment } & 16.0 & 11.9 & 16.0 & 11.9 & 15.5 & 11.4 & 15.1 & 10.9 & 14.0 & 10.2 \\ \text { Other benefits } & 3.8 & 4.0 & 3.2 & 3.3 & 2.9 & 3.1 & 2.6 & 2.9 & 2.7 & 2.9 \\ \text { Parenting } & 6.6 & 6.2 & 6.9 & 6.5 & 6.7 & 6.4 & 6.1 & 6.0 & 6.0 & 5.7 \\ \text { Sole parent } & 0.7 & 6.7 & 0.7 & 6.8 & 1.0 & 7.0 & 1.0 & 7.1 & 0.7 & 7.3 \\ \text { Other pensions } & 9.9 & 14.7 & 10.0 & 15.2 & 9.9 & 15.0 & 10.1 & 15.0 & 10.2 & 14.9\end{array}$

\section{Income Distribution Surveys}

\begin{tabular}{lcccc} 
Unemployment & 10.2 & 8.3 & 11.0 & 8.4 \\
Other benefits & 1.7 & 2.1 & 1.7 & 1.4 \\
Parenting & 10.8 & 10.7 & 10.4 & 10.3 \\
Sole parent & 0.9 & 5.3 & 1.2 & 5.6 \\
Other pensions & 9.4 & 10.7 & 8.5 & 10.3 \\
\hline
\end{tabular}

Table 3: IS recipiency rates by payment type (weekly/fortnightly) - Persons aged 25-64 (\%)

\begin{tabular}{ccccc}
\hline $1995-6$ & $1996-7$ & $1997-8$ & $1998-9$ & $1999-2000$ \\
\hline Males Females & Males Females & Males Females & Males Females & Males Females
\end{tabular}

\section{Longitudinal Data Set (fortnightly)}

\begin{tabular}{lcccccccccc} 
Unemployment & 9.7 & 7.0 & 9.8 & 7.1 & 9.7 & 6.8 & 9.5 & 6.6 & 8.7 & 6.1 \\
Other benefits & 2.3 & 2.3 & 1.9 & 2.1 & 1.8 & 1.9 & 1.7 & 2.0 & 1.7 & 2.0 \\
Parenting & 4.1 & 3.8 & 4.4 & 4.2 & 4.3 & 4.2 & 4.2 & 4.0 & 4.0 & 3.8 \\
Sole parent & 0.4 & 5.2 & 0.5 & 5.4 & 0.5 & 5.5 & 0.5 & 5.6 & 0.5 & 5.9 \\
Other pensions & 8.7 & 13.2 & 8.8 & 13.3 & 8.8 & 13.4 & 8.9 & 13.4 & 9.0 & 13.3 \\
\hline
\end{tabular}

\section{Income Distribution Surveys (weekly)}

\begin{tabular}{lcccccc} 
Unemployment & 8.0 & 5.9 & 7.7 & 6.1 & 7.9 & 5.7 \\
Other benefits & 1.8 & 1.9 & 1.7 & 1.8 & 1.4 & 1.3 \\
Parenting & 4.4 & 4.3 & 10.8 & 10.2 & 10.1 & 9.6 \\
Sole parent & 0.4 & 4.2 & 0.4 & 5.0 & 0.5 & 5.3 \\
Other pensions & 8.9 & 10.4 & 9.5 & 10.7 & 8.8 & 10.1 \\
\hline
\end{tabular}


Table 4: IDS estimates of annual reliance - Persons aged 15-64

$\begin{array}{lllllll}1981-2 & 1985-6 & 1989-90 & 1993-4 & 1994-5 & 1995-6 & 1996-7\end{array}$

\section{Recipiency Rates (\%)}

$\begin{array}{llllllll}\text { IS \& NIS pmts } & 62.9 & 62.4 & 52.0 & 48.4 & 48.1 & 48.6 & 47.4 \\ \text { IS pmts } & 23.2 & 25.8 & 22.3 & 26.9 & 28.8 & 34.7 & 33.5\end{array}$

Dependency Rates (\%)

Including both IS and NIS payments for all persons

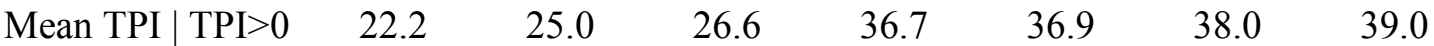

Excluding all NIS payments

$\begin{array}{llllllll}\text { Mean TPI } \mid \text { TPI }>0 & 50.6 & 51.9 & 52.8 & 54.8 & 50.5 & 44.7 & 45.6\end{array}$

Including NIS payments for IS recipients only

$\begin{array}{llllllll}\text { Mean TPI } \mid \mathrm{TPI}>0 & 53.0 & 54.2 & 55.5 & 60.5 & 56.9 & 50.9 & 52.5\end{array}$

Prop. with TPI in interval $\mid \mathrm{TPI}>0$ :

$\begin{array}{rlllllll}0-<25 & 39.0 & 36.7 & 35.4 & 29.1 & 31.7 & 40.3 & 37.0 \\ 25-<75 & 18.0 & 20.8 & 20.1 & 21.9 & 24.5 & 20.3 & 23.5 \\ 75-<100 & 17.9 & 18.4 & 22.1 & 20.4 & 17.3 & 15.4 & 15.2 \\ 100 & 25.1 & 24.1 & 22.4 & 28.7 & 26.4 & 24.1 & 24.4\end{array}$

\begin{tabular}{llllllll} 
Mean TPI (All) & 12.3 & 14.0 & 12.4 & 16.3 & 16.4 & 17.7 & 17.6 \\
\hline
\end{tabular}


Table 5: IDS estimates of annual reliance by sex and age

\begin{tabular}{|c|c|c|c|c|c|c|}
\hline & \multicolumn{2}{|c|}{$1981-2$} & \multicolumn{2}{|c|}{$1989-90$} & \multicolumn{2}{|c|}{$1996-7$} \\
\hline & Males & Females & Males & Females & Males & Females \\
\hline & \multicolumn{6}{|c|}{ IS Recipiency Rate (\%) } \\
\hline Age Group (yrs): & & & & & & \\
\hline $15-19$ & 26.3 & 31.2 & 24.8 & 31.6 & 35.4 & 40.0 \\
\hline $20-24$ & 26.0 & 27.5 & 23.7 & 27.4 & 30.3 & 34.1 \\
\hline $25-29$ & 16.8 & 18.2 & 16.2 & 20.8 & 28.9 & 35.1 \\
\hline $30-39$ & 12.6 & 16.2 & 13.0 & 17.5 & 33.7 & 37.3 \\
\hline $40-49$ & 12.1 & 18.3 & 13.8 & 18.6 & 24.3 & 28.8 \\
\hline $50-59$ & 18.9 & 34.7 & 19.2 & 31.8 & 28.1 & 33.0 \\
\hline $60-64$ & 48.9 & 72.1 & 39.5 & 63.2 & 46.4 & 69.6 \\
\hline \multirow[t]{2}{*}{ All aged 15-64 } & 19.8 & 26.8 & 18.8 & 25.9 & 30.7 & 36.3 \\
\hline & \multicolumn{6}{|c|}{ Mean TPI $\mid$ TPI $>0(\%)^{*}$} \\
\hline Age Group (yrs): & & & & & & \\
\hline $15-19$ & 45.2 & 48.4 & 41.7 & 47.8 & 54.4 & 50.4 \\
\hline $20-24$ & 38.4 & 44.6 & 44.3 & 53.3 & 49.3 & 53.9 \\
\hline $25-29$ & 37.5 & 53.1 & 41.6 & 55.5 & 47.2 & 50.2 \\
\hline $30-39$ & 40.7 & 53.6 & 47.8 & 56.0 & 40.0 & 41.5 \\
\hline $40-49$ & 47.5 & 57.8 & 50.4 & 53.1 & 41.6 & 49.3 \\
\hline $50-59$ & 52.1 & 64.2 & 63.0 & 71.7 & 61.4 & 73.3 \\
\hline $60-64$ & 62.3 & 74.7 & 67.7 & 72.2 & 75.9 & 73.6 \\
\hline All aged 15-64 & 46.5 & 58.0 & 50.8 & 59.0 & 50.2 & 54.4 \\
\hline
\end{tabular}

* NIS payments included only for IS-recipients.

Table 6: IDS estimates of annual reliance by family type - Persons aged 15-64 years

\begin{tabular}{|c|c|c|c|c|c|c|c|c|}
\hline & \multicolumn{2}{|c|}{$1981-2$} & \multicolumn{2}{|c|}{$1989-90$} & \multicolumn{2}{|c|}{$1996-7^{(\mathrm{a})}$} & \multicolumn{2}{|c|}{$1996-7^{(b)}$} \\
\hline & Males & Females & Males & Females & Males & Females & Males & Females \\
\hline & \multicolumn{8}{|c|}{ IS Recipiency Rate (\%) } \\
\hline Single, no dep. & 26.2 & 38.3 & 23.6 & 35.0 & 29.3 & 34.1 & 29.3 & 34.1 \\
\hline Couple, no dep. & 21.4 & 27.7 & 18.2 & 23.7 & 22.4 & 27.7 & 22.4 & 27.6 \\
\hline Single, with dep. & 45.9 & 70.5 & 48.4 & 70.6 & 58.1 & 72.7 & 56.6 & 70.6 \\
\hline \multirow[t]{2}{*}{ Couple, with dep. } & 13.6 & 13.7 & 14.6 & 15.4 & 35.4 & 35.8 & 20.6 & 21.0 \\
\hline & \multicolumn{8}{|c|}{ Mean TPI $\mid$ TPI $>0(\%)^{*}$} \\
\hline Single, no dep. & 50.0 & 61.9 & 56.7 & 65.5 & 69.5 & 71.0 & 69.5 & 71.0 \\
\hline Couple, no dep. & 47.0 & 56.1 & 51.4 & 58.2 & 58.3 & 61.9 & 58.3 & 62.0 \\
\hline Single, with dep. & 65.5 & 78.0 & 65.6 & 71.5 & 62.0 & 71.5 & 63.5 & 71.3 \\
\hline Couple, with dep. & 39.1 & 39.4 & 41.6 & 42.9 & 33.7 & 34.6 & 47.2 & 48.4 \\
\hline
\end{tabular}

Notes: (a) Parenting payment treated as IS

(b) Parenting payment treated as NIS

* NIS payments included only for IS-recipients. 
Table 7: IDS estimates of annual reliance by birthplace - Persons aged 15-64 years

\begin{tabular}{|c|c|c|c|c|c|c|}
\hline & \multicolumn{2}{|c|}{$1981-2$} & \multicolumn{2}{|c|}{$1989-90$} & \multicolumn{2}{|c|}{ 1996-7 } \\
\hline & Males & Females & Males & Females & Males & Females \\
\hline & \multicolumn{6}{|c|}{ IS Recipiency Rate (\%) } \\
\hline Native-born & 19.6 & 27.0 & 18.6 & 25.3 & 30.3 & 35.8 \\
\hline \multirow[t]{2}{*}{ Foreign-born } & 20.2 & 26.2 & 19.3 & 27.7 & 32.1 & 37.7 \\
\hline & \multicolumn{6}{|c|}{ Mean TPI $\mid$ TPI $>0(\%)^{*}$} \\
\hline Native-born & 46.2 & 57.6 & 48.4 & 57.3 & 47.5 & 51.5 \\
\hline Foreign-born & 47.1 & 59.3 & 57.2 & 63.9 & 57.6 & 62.2 \\
\hline
\end{tabular}

* NIS payments included only for IS-recipients.

Table 8: IDS estimates of annual reliance by educational attainment - Persons aged 15-64 years

\begin{tabular}{|c|c|c|c|c|c|c|}
\hline & \multicolumn{2}{|c|}{$1981-2$} & \multicolumn{2}{|c|}{$1989-90$} & \multicolumn{2}{|c|}{ 1996-7 } \\
\hline & Males & Females & Males & Females & Males & Females \\
\hline & \multicolumn{6}{|c|}{ IS Recipiency Rate (\%) } \\
\hline Degree & 14.6 & 18.4 & 9.0 & 13.4 & 15.7 & 15.2 \\
\hline Other Qual. & 15.8 & 20.4 & 15.0 & 19.7 & 27.8 & 32.5 \\
\hline \multirow[t]{2}{*}{ No Qual. } & 23.5 & 30.3 & 23.8 & 31.1 & 36.7 & 43.1 \\
\hline & \multicolumn{6}{|c|}{ Mean TPI $\mid$ TPI $>0(\%)^{*}$} \\
\hline Degree & 25.3 & 30.5 & 33.5 & 35.6 & 29.7 & 32.9 \\
\hline Other Qual. & 39.5 & 48.2 & 44.3 & 49.5 & 41.5 & 48.1 \\
\hline No Qual. & 51.1 & 61.5 & 55.6 & 63.9 & 57.4 & 58.9 \\
\hline
\end{tabular}

* NIS payments included only for IS-recipients. 
Table 9: IDS estimates of annual reliance by payment type - Persons aged 15-64 years

\begin{tabular}{|c|c|c|c|c|c|c|}
\hline & \multicolumn{2}{|c|}{$1981-2$} & \multicolumn{2}{|c|}{$1989-90$} & \multicolumn{2}{|c|}{ 1996-7 } \\
\hline & Males & Females & Males & Females & Males & Females \\
\hline & \multicolumn{6}{|c|}{ IS Recipiency Rate (\%) } \\
\hline Unemployment & 9.4 & 8.3 & 8.3 & 7.3 & 12.5 & 10.3 \\
\hline Other allowances & 3.2 & 3.1 & 2.6 & 2.6 & 1.7 & 1.6 \\
\hline Education & 2.4 & 2.6 & 3.1 & 3.7 & 5.3 & 6.5 \\
\hline Parenting & 0.0 & 0.0 & 0.0 & 0.0 & 9.4 & 9.6 \\
\hline Sole parent & 0.6 & 2.9 & 1.0 & 4.7 & 1.4 & 5.8 \\
\hline \multirow[t]{2}{*}{ Other pensions } & 5.8 & 9.6 & 5.3 & 7.9 & 8.0 & 9.2 \\
\hline & \multicolumn{6}{|c|}{ Mean TPI $\mid$ TPI $>0(\%)$} \\
\hline Unemployment & 37.2 & 34.9 & 42.6 & 41.7 & 41.7 & 36.4 \\
\hline Other allowances & 27.1 & 31.7 & 30.8 & 31.6 & 31.4 & 22.2 \\
\hline Education & 22.9 & 21.4 & 24.2 & 24.6 & 22.2 & 22.0 \\
\hline Parenting & 0.0 & 0.0 & 0.0 & 0.0 & 11.4 & 12.3 \\
\hline Sole parent & 31.7 & 62.4 & 40.7 & 58.4 & 26.9 & 39.9 \\
\hline Other pensions & 58.4 & 62.6 & 62.9 & 64.1 & 62.5 & 61.1 \\
\hline
\end{tabular}

Mean TPI | TPI $>0$ by main payment type $(\%)^{*}$

\begin{tabular}{lcccccc} 
Unemployment & 42.0 & 41.6 & 48.9 & 49.4 & 55.5 & 54.7 \\
Other allowances & 37.9 & 47.0 & 42.6 & 46.5 & 58.9 & 44.9 \\
Education & 26.1 & 26.0 & 27.8 & 29.3 & 34.6 & 35.9 \\
Parenting & - & - & - & - & 21.9 & 23.4 \\
Sole parent & 44.8 & 74.7 & 51.3 & 70.3 & 51.6 & 68.2 \\
Other pensions & 65.8 & 72.0 & 70.6 & 72.2 & 76.1 & 75.6 \\
\hline
\end{tabular}

* The mean TPI is for all (IS and NIS) payments, with an individual classified according to the most important payment type of the income unit to which that individual belongs.

Table 10: Decompositions of changes in the mean TPI in the population aged 15-64 years, 1981-2 to 1996-7 - IDS

\begin{tabular}{|c|c|c|c|c|}
\hline & \multicolumn{2}{|c|}{ A } & \multicolumn{2}{|c|}{$\mathrm{B}$} \\
\hline & Composition effect & Within-group effect & Composition effect & Within-group effect \\
\hline Family type & 0.66 & 4.58 & 0.43 & 4.81 \\
\hline Birthplace & 0.02 & 5.25 & 0.04 & 5.24 \\
\hline Education & -0.81 & 5.99 & -1.37 & 6.55 \\
\hline Age & -0.32 & 5.60 & -0.41 & 5.69 \\
\hline
\end{tabular}


Table 11: TTO (1995-2000) by birth cohort (age in January 1995) - Persons aged 15-64

\begin{tabular}{|c|c|c|c|c|c|c|c|c|c|c|}
\hline & \multicolumn{5}{|c|}{ Males } & \multicolumn{5}{|c|}{ Females } \\
\hline & \multicolumn{4}{|c|}{ Proportion in TTO interval (\%) } & \multirow[b]{2}{*}{$\begin{array}{l}\text { Mean } \\
\text { TTO }\end{array}$} & \multicolumn{4}{|c|}{ Proportion in TTO interval (\%) } & \multirow[b]{2}{*}{$\begin{array}{c}\text { Mean } \\
\text { TTO }\end{array}$} \\
\hline & $\begin{array}{c}\text { Low } \\
(1-24)\end{array}$ & $\begin{array}{c}\text { Med. } \\
(25-74)\end{array}$ & $\begin{array}{c}\text { High } \\
(75-99)\end{array}$ & $\begin{array}{l}\text { Max. } \\
\text { (100) }\end{array}$ & & $\begin{array}{c}\text { Low } \\
(1-24)\end{array}$ & $\begin{array}{c}\text { Med. } \\
(25-74)\end{array}$ & $\begin{array}{c}\text { High } \\
(75-99)\end{array}$ & $\begin{array}{l}\text { Max. } \\
(100)\end{array}$ & \\
\hline Age Grou & & & & & & & & & & \\
\hline $10-14$ & 78.8 & 20.7 & 0.5 & 0.0 & 0.152 & 73.9 & 25.0 & 1.2 & 0.0 & 0.169 \\
\hline $15-19$ & 57.6 & 33.1 & 8.3 & 1.0 & 0.287 & 54.8 & 30.3 & 13.1 & 1.9 & 0.324 \\
\hline $20-24$ & 53.1 & 32.3 & 12.5 & 2.1 & 0.329 & 48.7 & 29.3 & 17.4 & 4.6 & 0.387 \\
\hline $25-34$ & 47.0 & 33.1 & 14.7 & 5.2 & 0.384 & 38.3 & 31.1 & 20.5 & 10.0 & 0.473 \\
\hline $35-44$ & 40.2 & 31.7 & 17.2 & 10.9 & 0.450 & 33.6 & 30.4 & 20.4 & 15.5 & 0.517 \\
\hline $45-54$ & 32.3 & 28.5 & 17.5 & 21.7 & 0.544 & 25.3 & 26.7 & 19.5 & 28.6 & 0.618 \\
\hline $55-64$ & 13.3 & 21.1 & 20.5 & 45.1 & 0.762 & 7.9 & 16.6 & 19.6 & 55.9 & 0.835 \\
\hline All ages & 42.4 & 29.7 & 14.6 & 13.4 & 0.444 & 35.0 & 27.2 & 18.1 & 19.8 & 0.525 \\
\hline
\end{tabular}

Table 12: TTO (1995-2000) by birthplace and ethnic group - Persons aged 15-64 years

\begin{tabular}{|c|c|c|c|c|c|c|c|c|c|c|}
\hline & \multicolumn{5}{|c|}{ Males } & \multicolumn{5}{|c|}{ Females } \\
\hline & \multicolumn{4}{|c|}{ Proportion in TTO interval (\%) } & \multirow[b]{2}{*}{$\begin{array}{c}\text { Mean } \\
\text { TTO }\end{array}$} & \multicolumn{4}{|c|}{ Proportion in TTO interval (\%) } & \multirow[b]{2}{*}{$\begin{array}{l}\text { Mean } \\
\text { TTO }\end{array}$} \\
\hline & $\begin{array}{c}\text { Low } \\
(1-24)\end{array}$ & $\begin{array}{c}\text { Med. } \\
(25-74)\end{array}$ & $\begin{array}{c}\text { High } \\
(75-99)\end{array}$ & $\begin{array}{l}\text { Max. } \\
(100)\end{array}$ & & $\begin{array}{c}\text { Low } \\
(1-24)\end{array}$ & $\begin{array}{l}\text { Med. } \\
(25-74)\end{array}$ & $\begin{array}{c}\text { High } \\
(75-99)\end{array}$ & $\begin{array}{l}\text { Max. } \\
(100)\end{array}$ & \\
\hline Aus. born & 43.6 & 29.9 & 14.3 & 12.1 & 0.431 & 37.0 & 27.1 & 17.6 & 18.3 & 0.506 \\
\hline Foreign born & 38.3 & 29.1 & 15.5 & 17.1 & 0.485 & 29.4 & 27.2 & 19.5 & 23.9 & 0.578 \\
\hline Non-ATSI & 42.6 & 29.5 & 14.4 & 13.5 & 0.443 & 35.3 & 27.1 & 17.8 & 19.9 & 0.523 \\
\hline ATSI & 31.0 & 38.3 & 24.2 & 6.5 & 0.516 & 18.4 & 32.5 & 35.0 & 14.1 & 0.642 \\
\hline
\end{tabular}

Table 13: TTO (1995-2000) by numbers of spells - Persons aged 15-64 years

\begin{tabular}{|c|c|c|c|c|c|c|c|c|c|c|}
\hline & \multicolumn{5}{|c|}{ Males } & \multicolumn{5}{|c|}{ Females } \\
\hline & \multicolumn{4}{|c|}{ Proportion in TTO interval (\%) } & \multirow[b]{2}{*}{$\begin{array}{c}\text { Mean } \\
\text { TTO }\end{array}$} & \multicolumn{4}{|c|}{ Proportion in TTO interval (\%) } & \multirow[b]{2}{*}{$\begin{array}{c}\text { Mean } \\
\text { TTO }\end{array}$} \\
\hline & $\begin{array}{c}\text { Low } \\
(1-24)\end{array}$ & $\begin{array}{l}\text { Med. } \\
(25-74)\end{array}$ & $\begin{array}{c}\text { High } \\
(75-99)\end{array}$ & $\begin{array}{l}\text { Max. } \\
(100)\end{array}$ & & $\begin{array}{c}\text { Low } \\
(1-24)\end{array}$ & $\begin{array}{l}\text { Med. } \\
(25-74)\end{array}$ & $\begin{array}{c}\text { High } \\
(75-99)\end{array}$ & $\begin{array}{l}\text { Max. } \\
(100)\end{array}$ & \\
\hline \multicolumn{11}{|l|}{ No. of spells } \\
\hline 1 & 46.8 & 18.0 & 13.1 & 22.1 & 0.462 & 36.3 & 18.1 & 16.8 & 28.8 & 0.559 \\
\hline 2 & 44.0 & 36.2 & 19.9 & 0.0 & 0.395 & 36.0 & 39.7 & 24.3 & 0.0 & 0.448 \\
\hline 3 & 31.6 & 52.4 & 16.0 & 0.0 & 0.432 & 29.5 & 52.8 & 17.7 & 0.0 & 0.448 \\
\hline 4 & 19.9 & 67.6 & 12.5 & 0.0 & 0.455 & 20.0 & 67.9 & 12.1 & 0.0 & 0.463 \\
\hline $5+$ & 11.4 & 82.8 & 5.9 & 0.0 & 0.466 & 15.4 & 77.7 & 6.9 & 0.0 & 0.446 \\
\hline $\begin{array}{l}\text { Avg. no. of } \\
\text { spells }\end{array}$ & 1.48 & 2.32 & 1.69 & 1.00 & & 1.40 & 1.96 & 1.49 & 1.00 & \\
\hline
\end{tabular}


Table 14: Proportion of time with different family circumstances by TTO (1995-2000) Persons aged 15-64 years (\%)

\begin{tabular}{|c|c|c|c|c|c|c|c|c|}
\hline & \multicolumn{4}{|c|}{ Males: TTO interval } & \multicolumn{4}{|c|}{ Females: TTO interval } \\
\hline & $\begin{array}{c}\text { Low } \\
(1-24)\end{array}$ & $\begin{array}{c}\text { Med. } \\
(25-74)\end{array}$ & $\begin{array}{c}\text { High } \\
(75-99)\end{array}$ & $\begin{array}{l}\text { Max. } \\
(100)\end{array}$ & $\begin{array}{c}\text { Low } \\
(1-24)\end{array}$ & $\begin{array}{l}\text { Med. } \\
(25-74)\end{array}$ & $\begin{array}{c}\text { High } \\
(75-99)\end{array}$ & $\begin{array}{l}\text { Max. } \\
(100)\end{array}$ \\
\hline Single w/o children & 60.5 & 52.7 & 49.9 & 36.7 & 51.3 & 32.3 & 27.5 & 32.6 \\
\hline Couple w/o children & 24.7 & 29.7 & 29.8 & 51.4 & 18.2 & 23.2 & 23.1 & 45.4 \\
\hline Single with children & 0.9 & 2.0 & 3.1 & 1.7 & 10.1 & 21.2 & 29.3 & 14.6 \\
\hline Couple with children & 13.8 & 15.6 & 17.2 & 10.3 & 20.5 & 23.3 & 20.2 & 7.4 \\
\hline Single & 61.4 & 54.7 & 52.9 & 38.3 & 61.4 & 53.5 & 56.8 & 47.2 \\
\hline Couple, both on IS & 17.0 & 24.4 & 34.3 & 54.9 & 17.0 & 25.7 & 31.8 & 49.5 \\
\hline Couple, one on IS & 21.6 & 20.9 & 12.8 & 6.8 & 21.6 & 20.8 & 11.4 & 3.3 \\
\hline No. of obs. & 11,994 & 8,398 & 4,135 & 3,792 & 10,566 & 8,198 & 5,460 & 5,972 \\
\hline
\end{tabular}

Table 15: One-year TTO over time - Persons aged 15-64 years

\begin{tabular}{lcccccr}
\hline \multicolumn{5}{c}{ Proportion in TTO interval (\%) } & Mean TTO & No. of obs. \\
\hline & $\begin{array}{c}\text { Low } \\
(1-24 \%)\end{array}$ & $\begin{array}{c}\text { Med. } \\
(25-74 \%)\end{array}$ & $\begin{array}{c}\text { High } \\
(75-99 \%)\end{array}$ & $\begin{array}{c}\text { Max. } \\
(100 \%)\end{array}$ & & \\
1995 & 15.52 & 27.07 & 16.34 & 41.07 & 0.711 & 34,520 \\
1996 & 14.74 & 22.02 & 15.61 & 47.63 & 0.743 & 35,924 \\
1997 & 14.01 & 21.57 & 13.52 & 50.91 & 0.754 & 35,804 \\
1998 & 13.89 & 20.91 & 12.45 & 52.75 & 0.759 & 35,909 \\
1999 & 14.35 & 20.71 & 11.69 & 53.25 & 0.754 & 35,646 \\
\hline
\end{tabular}

Table 16: Movement between one-year TTO groups - 1998 and 1999 - Persons aged 15-64 years

Proportion in each pair of TTO groups (\%)

\begin{tabular}{lcccccr}
\hline \multicolumn{7}{c}{ TTO (1999) } \\
$\begin{array}{lccccc}\text { TTO (1998) } \\
\text { Min. (0\%) }\end{array}$ & Min. (0\%) & Low (1-24\%) & Med. (25-74\%) & High (75-99\%) & Max. (100\%) & Total \\
Low (1-24\%) & 0.00 & 6.63 & 6.59 & 1.61 & 0.17 & 14.99 \\
Med. (25-74\%) & 6.21 & 1.72 & 2.21 & 0.80 & 1.15 & 12.09 \\
High (75-99\%) & 6.38 & 2.19 & 4.03 & 2.01 & 3.59 & 18.19 \\
Max. (100\%) & 1.08 & 0.79 & 2.12 & 2.02 & 4.24 & 10.25 \\
& 0.13 & 0.87 & 2.81 & 3.67 & 37.00 & 44.48 \\
Total & 13.79 & 12.20 & 17.76 & 10.10 & 46.15 & 100.00 \\
\hline
\end{tabular}


Table17: Persistence of heavy reliance - Persons aged 15-64 years

\begin{tabular}{lccccc}
\hline & \multicolumn{5}{c}{$\begin{array}{c}\text { Probability of remaining heavily reliant: Conditional } \\
\text { probability }(\text { TTO }>0.5)\end{array}$} \\
\cline { 2 - 6 } & 1995 & 1996 & 1997 & 1998 & 1999 \\
Condition: & & & & & \\
TTO $(1995)>0.5$ & 1 & 0.84 & 0.78 & 0.74 & 0.71 \\
TTO $(1996)>0.5$ & & 1 & 0.83 & 0.77 & 0.72 \\
TTO $(1997)>0.5$ & & & 1 & 0.84 & 0.77 \\
TTO $(1998)>0.5$ & & & & 1 & 0.84 \\
TTO $(1999)>0.5$ & & & & & 1 \\
\hline
\end{tabular}

Probability of exiting benefits: Conditional probability

\begin{tabular}{llccc}
\multicolumn{5}{c}{$($ TTO =0) } \\
\hline 1995 & 1996 & 1997 & 1998 & 1999
\end{tabular}

Condition:

\begin{tabular}{lccccc} 
TTO $(1995)>0.5$ & 0 & 0.06 & 0.14 & 0.18 & 0.22 \\
TTO $(1996)>0.5$ & & 0 & 0.06 & 0.15 & 0.19 \\
TTO $(1997)>0.5$ & & & 0 & 0.07 & 0.14 \\
TTO $(1998)>0.5$ & & & & 0 & 0.06 \\
TTO $(1999)>0.5$ & & & & & 0 \\
\hline
\end{tabular}


Figure 1: TTO Distribution - 1995-2000
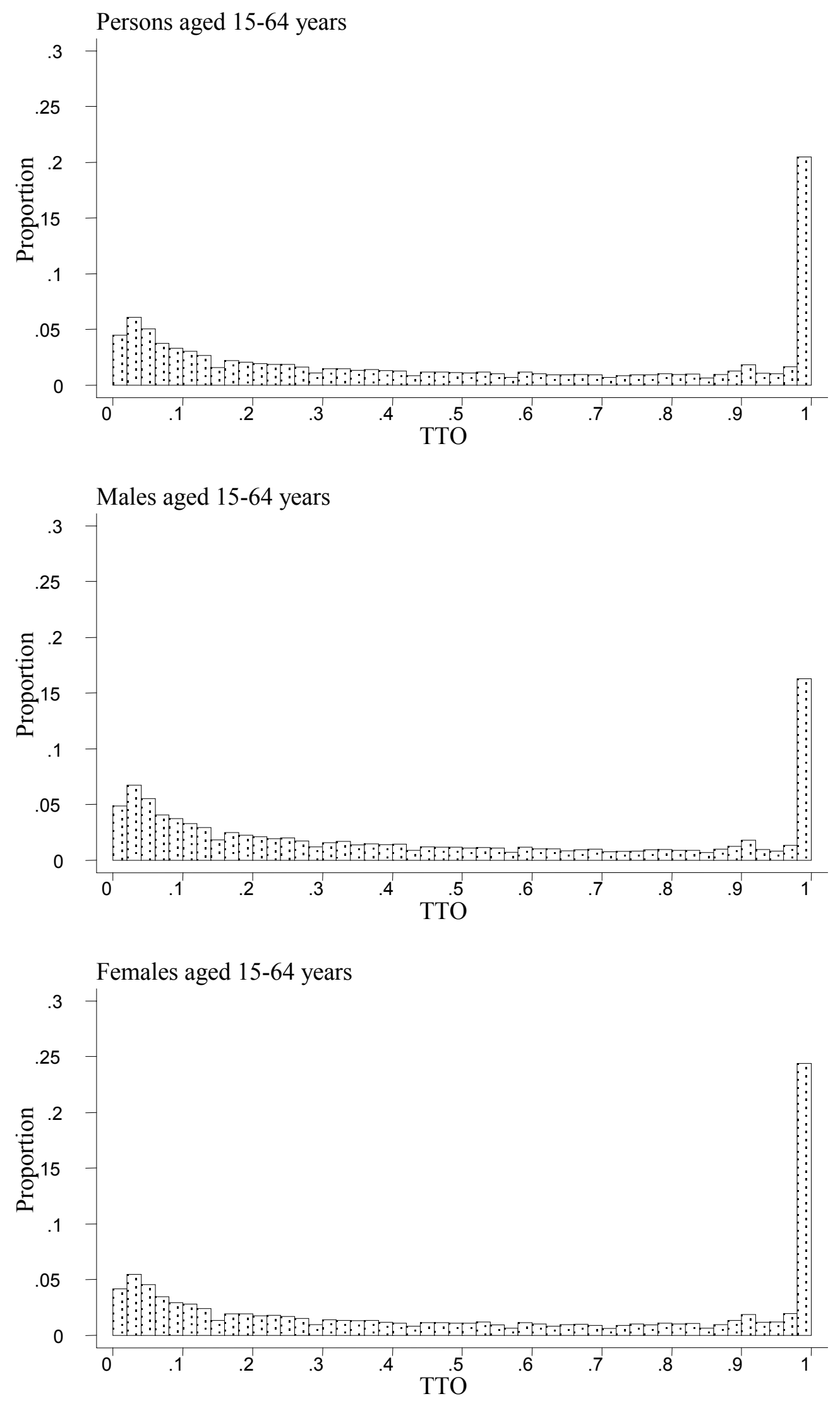
Figure 2: Distribution of TTO by payment type - Persons aged 15-64 years - 1995-2000
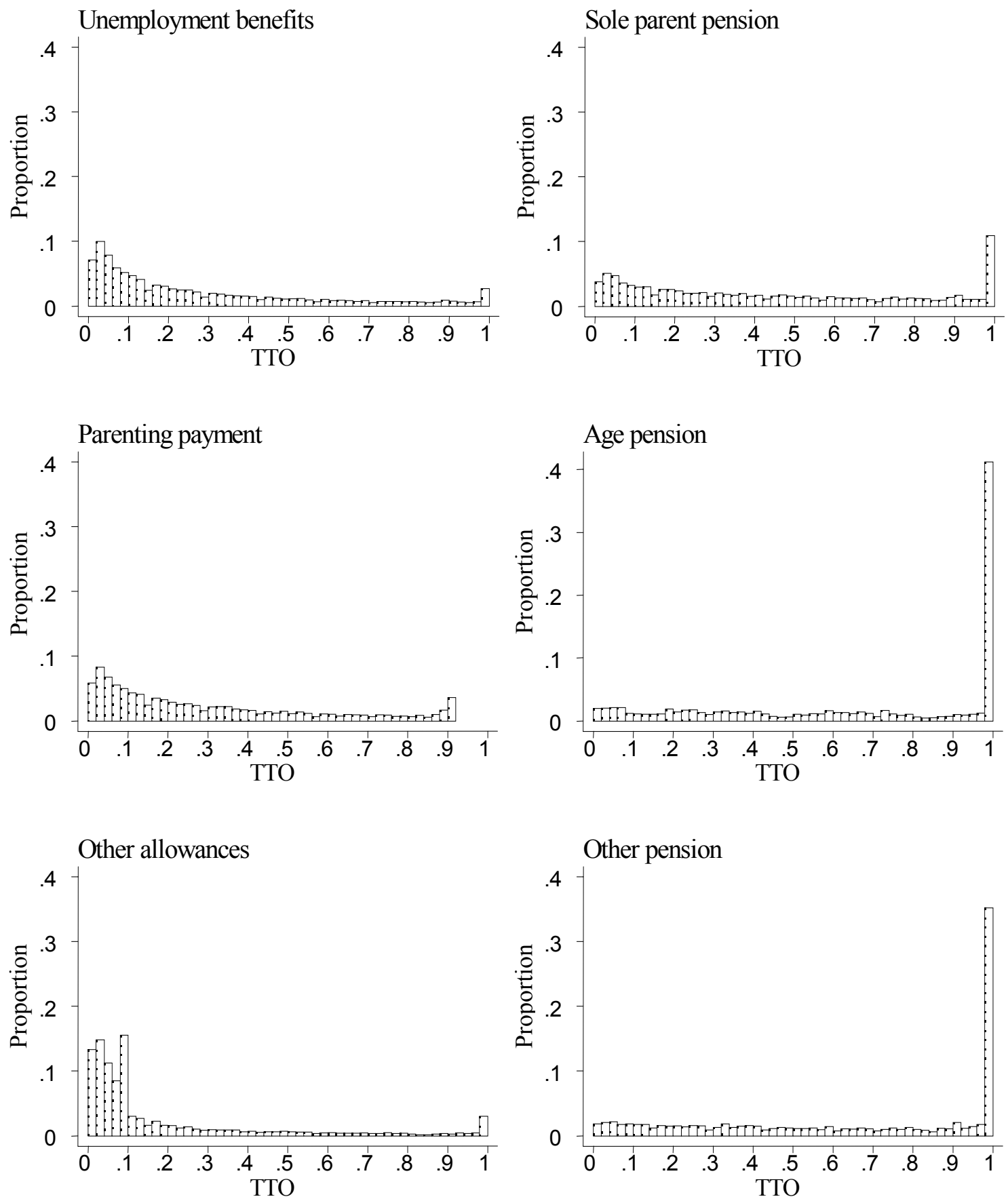

Number (proportion) of income units in each payment type subsample:

Unemployment benefit $39907(0.67)$

Sole parents pension

$7755(0.13)$

Other Allowances

$12942(0.22)$

Age pension

$7628(0.12)$

Parenting payments

$13453(0.23)$

Other pension

$13604(0.23)$ 


\section{Appendix A: Classification of payment type categories}

Table A1: Payment types treated as income support payments in the IDS

\begin{tabular}{|c|c|c|c|c|}
\hline 1981-2 & 1986 & 1990 & $1994-5,1995-6$ & $1996-7,1997-8$ \\
\hline & & Unemployment & & \\
\hline \multirow[t]{4}{*}{$\begin{array}{l}\text { Unemployment } \\
\text { benefit }\end{array}$} & $\begin{array}{c}\text { Unemployment } \\
\text { benefit }\end{array}$ & $\begin{array}{c}\text { Unemployment } \\
\text { benefit }\end{array}$ & Job search allowance & Newstart allowance \\
\hline & & & Newstart allowance & $\begin{array}{l}\text { Mature age } \\
\text { allowance }\end{array}$ \\
\hline & & & $\begin{array}{l}\text { Mature age } \\
\text { allowance }\end{array}$ & $\begin{array}{l}\text { Youth training } \\
\text { allowance }\end{array}$ \\
\hline & & & $\begin{array}{l}\text { Youth training } \\
\text { allowance }\end{array}$ & \\
\hline
\end{tabular}

\begin{tabular}{|c|c|c|c|c|}
\hline \\
\hline \multicolumn{5}{|c|}{ Other allowances } \\
\hline Sickness benefit & Sickness benefit & Sickness benefit & Sickness allowance & Sickness allowance \\
\hline \multirow{2}{*}{$\begin{array}{l}\text { Other government } \\
\text { benefit }\end{array}$} & Special benefit & Special benefit & Special benefit & Special benefit \\
\hline & $\begin{array}{c}\text { Other government } \\
\text { pensions and } \\
\text { benefits }\end{array}$ & $\begin{array}{c}\text { Other government } \\
\text { pensions and } \\
\text { benefits }\end{array}$ & $\begin{array}{l}\text { Other government } \\
\text { pensions and } \\
\text { allowances }\end{array}$ & $\begin{array}{l}\text { Other government } \\
\text { cash transfers }\end{array}$ \\
\hline \multicolumn{5}{|c|}{ Education } \\
\hline $\begin{array}{l}\text { Self education } \\
\text { assistance (TEAS } \\
\text { and secondary }\end{array}$ & $\begin{array}{c}\text { Secondary education } \\
\text { scheme }\end{array}$ & $\begin{array}{l}\text { Secondary education } \\
\text { Austudy scheme }\end{array}$ & Austudy/Abstudy & Austudy/Abstudy \\
\hline $\begin{array}{c}\text { education } \\
\text { assistance) }\end{array}$ & $\begin{array}{l}\text { Tertiary education } \\
\text { assistance scheme }\end{array}$ & $\begin{array}{l}\text { Tertiary education } \\
\text { Austudy scheme }\end{array}$ & & \\
\hline
\end{tabular}

\begin{tabular}{|c|c|c|c|c|}
\hline \multicolumn{5}{|c|}{ Parenting } \\
\hline - & - & - & Parenting allowance & Parenting allowance \\
\hline
\end{tabular}

\begin{tabular}{|c|c|c|c|c|}
\hline & & Sole parent & & \\
\hline $\begin{array}{c}\text { Supporting parent's } \\
\text { benefit }\end{array}$ & $\begin{array}{c}\text { Supporting parent's } \\
\text { benefit }\end{array}$ & Sole parent's benefit & Sole parent pension & Sole parent pension \\
\hline
\end{tabular}

\begin{tabular}{|c|c|c|c|c|}
\hline \multicolumn{5}{|c|}{ Other pensions } \\
\hline $\begin{array}{l}\text { War disability } \\
\text { pension }\end{array}$ & Disability pension & Disability pension & $\begin{array}{l}\text { Disability support } \\
\text { pension }\end{array}$ & $\begin{array}{l}\text { Disability support } \\
\text { pension }\end{array}$ \\
\hline $\begin{array}{l}\text { War widow's } \\
\text { pension }\end{array}$ & $\begin{array}{l}\text { War widow's } \\
\text { pension }\end{array}$ & $\begin{array}{l}\text { War widow's } \\
\text { pension }\end{array}$ & $\begin{array}{l}\text { War widow's } \\
\text { pension }\end{array}$ & $\begin{array}{l}\text { War widow's } \\
\text { pension }\end{array}$ \\
\hline Widow's pension & Widow's pension & & Widow pension & Widow's allowance \\
\hline Invalid pension & Invalid pension & Invalid pension & Wife/carer pension & Wife/carer pension \\
\hline Wife's pension & $\begin{array}{l}\text { Wife's/carer's } \\
\text { pension }\end{array}$ & $\begin{array}{l}\text { Wife's/carer's } \\
\text { pension }\end{array}$ & DVA service pension & DVA service pension \\
\hline & Service pension & Service pension & $\begin{array}{l}\text { DVA disability } \\
\text { pension }\end{array}$ & $\begin{array}{l}\text { DVA disability } \\
\text { pension }\end{array}$ \\
\hline
\end{tabular}

Partner allowance Partner allowance

Although not explicitly considered in the examination of reliance by payment type, age pensions are also treated as income support payments for the purposes of estimating reliance on all payment types collectively. 
Table A2: Payment types treated as non-income support payments in the IDS

\begin{tabular}{cccc}
\hline \hline $\mathbf{1 9 8 1 - 2}$ & $\mathbf{1 9 8 6 , 1 9 9 0}$ & $\mathbf{1 9 9 4 - 5 , \mathbf { 1 9 9 5 } - 6}$ & $\mathbf{1 9 9 6 - 7 , \mathbf { 1 9 9 7 - 8 }}$ \\
\hline Family allowance & Family allowance & $\begin{array}{c}\text { Family and additional } \\
\text { family payments }\end{array}$ & Family payments \\
$\begin{array}{c}\text { Childs education } \\
\text { assistance }\end{array}$ & Family supplement & $\begin{array}{c}\text { Child disability } \\
\text { allowance }\end{array}$ & $\begin{array}{c}\text { Child disability } \\
\text { allowance }\end{array}$ \\
& & Home child care \\
& allowance & \\
& & \\
\end{tabular}

Table A3: Classification of payment types in the LDS

\begin{tabular}{|c|c|}
\hline Payment type category & Payment type in LDS \\
\hline \multirow[t]{6}{*}{ Unemployment benefit } & Job seeker allowance \\
\hline & Youth training allowance \\
\hline & Mature age allowance \\
\hline & Newstart allowance \\
\hline & Youth allowance \\
\hline & Newstart Mature age allowance \\
\hline \multirow{9}{*}{ Other allowances } & Drought relief payment \\
\hline & Farm family restart scheme \\
\hline & Sickness allowance \\
\hline & Crisis payment (allowance) \\
\hline & Special benefit \\
\hline & Exceptional Circumstances payment \\
\hline & Bereavement allowance \\
\hline & Mature age partner allowance \\
\hline & Partner allowance* \\
\hline \multirow[t]{4}{*}{ Parenting payment } & Partner of dependent YA recipient \\
\hline & Partner of pension (PEN, DSP, AGE) recipient \\
\hline & Partner of person on low income \\
\hline & Partner of Newstart (NMA, NSA, SKA, AUS) recipient \\
\hline \multirow[t]{2}{*}{ Sole parent pension } & Sole parent pension \\
\hline & Parenting payment single \\
\hline Age pension & Age pension \\
\hline \multirow[t]{11}{*}{ Other pension } & Disability wage supplement \\
\hline & Disability support pension \\
\hline & Widow allowance \\
\hline & Widow pension \\
\hline & Rehabilitation allowance \\
\hline & Carer payment \\
\hline & Wife's pension age \\
\hline & Wife's disability support pension \\
\hline & Wife's disability wage supplement \\
\hline & Other pension payment \\
\hline & Crisis payment (pension) \\
\hline
\end{tabular}

\footnotetext{
* A person can qualify for Partner Allowance as either the partner of a pension recipient or the partner of an allowances recipient. It is therefore ambiguous whether Partner Allowance should be classified as "Other Allowance" or "Other pension", but we have classified it as "Other Allowance" because most partners were on unemployment benefits.
} 


\section{Appendix B: Sensitivity tests}

Table B1: Comparison of the LDS with the IDS: IS annual recipiency rates excluding parenting payments Persons aged 25-64 years $(\%)$

\begin{tabular}{|c|c|c|c|c|c|c|c|c|c|c|}
\hline & \multicolumn{2}{|c|}{$1995-6$} & \multicolumn{2}{|c|}{$1996-7$} & \multicolumn{2}{|c|}{$1997-8$} & \multicolumn{2}{|c|}{$1998-9$} & \multicolumn{2}{|c|}{$1999-2000$} \\
\hline & Males & emales & Males & Females & Males & Females & Males & Females & Males & Females \\
\hline & \multicolumn{10}{|c|}{ Longitudinal Data Set } \\
\hline All persons & \multicolumn{2}{|c|}{27.8} & \multicolumn{2}{|c|}{27.5} & \multicolumn{2}{|c|}{27.3} & \multicolumn{2}{|c|}{26.9} & \multicolumn{2}{|c|}{26.1} \\
\hline By gender & 25.2 & 30.3 & 24.9 & 30.2 & 24.7 & 29.8 & 24.3 & 29.5 & 23.3 & 28.9 \\
\hline \multicolumn{11}{|l|}{ By age group } \\
\hline $25-29$ & 27.6 & 27.9 & 26.4 & 28.1 & 26.1 & 27.0 & 25.2 & 26.5 & 23.7 & 25.8 \\
\hline $30-39$ & 22.0 & 25.3 & 21.8 & 25.1 & 21.8 & 24.8 & 21.8 & 24.7 & 20.5 & 24.3 \\
\hline $40-49$ & 19.0 & 22.6 & 18.8 & 22.2 & 18.9 & 22.2 & 18.9 & 22.5 & 18.3 & 22.5 \\
\hline $50-59$ & 26.9 & 36.4 & 26.8 & 36.0 & 26.4 & 35.3 & 24.8 & 34.0 & 23.8 & 32.3 \\
\hline $60-64$ & 53.1 & 68.3 & 52.2 & 68.7 & 50.3 & 69.4 & 50.6 & 67.4 & 49.2 & 66.0 \\
\hline
\end{tabular}

\section{Income Distribution Surveys}

\begin{tabular}{lcccc} 
All persons & \multicolumn{2}{c}{23.3} & \multicolumn{2}{c}{23.5} \\
& & & 20.6 & 26.4 \\
By gender & 20.0 & 26.5 & & \\
& & & & \\
By age group: & & & 23.2 & 26.0 \\
$25-29$ & 19.2 & 22.2 & 17.3 & 19.7 \\
$30-39$ & 14.2 & 21.0 & 13.7 & 19.2 \\
$40-49$ & 15.3 & 19.3 & 23.4 & 30.6 \\
$50-59$ & 24.2 & 33.3 & & \\
$60-64$ & 51.2 & 66.4 & 45.1 & 69.0 \\
\hline
\end{tabular}

Table B2: IDS aggregate annual reliance estimates treating parenting payments as non-income support payments

\begin{tabular}{lllllll}
$1981-2$ & $1985-6$ & $1989-90$ & $1993-4$ & $1994-5$ & $1995-6$ & $1996-7$ \\
\hline
\end{tabular}

IS Recipiency Rate (\%)

$\begin{array}{llllllll}\text { IS pmts } & 23.2 & 25.8 & 22.3 & 26.9 & 27.4 & 27.9 & 27.3\end{array}$

Dependency Rate - Including NIS payments for IS recipients only (\%)

\begin{tabular}{llllllll} 
Mean (all) & 12.3 & 14.0 & 12.4 & 16.3 & 16.2 & 16.8 & 16.6 \\
Mean | TPI $>0$ & 53.0 & 54.2 & 55.5 & 60.5 & 59.1 & 60.2 & 60.8 \\
& & & & & & & \\
$\begin{array}{l}\text { Prop. with TPI in } \\
\text { interval | TPI }>0 \text { : }\end{array}$ & & & & & & & \\
$0-<25$ & 39.0 & 36.7 & 35.4 & 29.1 & 29.2 & 29.1 & 27.3 \\
$25-<75$ & 18.0 & 20.8 & 20.1 & 21.9 & 25.0 & 22.7 & 25.0 \\
$75-<100$ & 17.9 & 18.4 & 22.1 & 20.4 & 18.2 & 19.0 & 18.2 \\
100 & 25.1 & 24.1 & 22.4 & 28.7 & 27.7 & 29.2 & 29.5 \\
\hline \hline
\end{tabular}


Table B3: Proportion of time with different family circumstances by TTO (1995-2000) - Persons aged 20-55 years - LDS (\%)

\begin{tabular}{|c|c|c|c|c|c|c|c|c|}
\hline & \multicolumn{4}{|c|}{ Males: TTO interval } & \multicolumn{4}{|c|}{ Females: TTO interval } \\
\hline & $\begin{array}{c}\text { Low } \\
(1-24)\end{array}$ & $\begin{array}{c}\text { Med. } \\
(25-74)\end{array}$ & $\begin{array}{c}\text { High } \\
(75-99)\end{array}$ & $\begin{array}{l}\text { Max. } \\
(100)\end{array}$ & $\begin{array}{c}\text { Low } \\
(1-24)\end{array}$ & $\begin{array}{c}\text { Med. } \\
(25-74)\end{array}$ & $\begin{array}{c}\text { High } \\
(75-99)\end{array}$ & $\begin{array}{l}\text { Max. } \\
(100)\end{array}$ \\
\hline Single w/o children & 50.3 & 48.6 & 52.7 & 51.0 & 37.7 & 25.3 & 23.6 & 28.4 \\
\hline Couple w/o children & 29.0 & 28.1 & 20.8 & 27.7 & 19.9 & 19.0 & 14.6 & 28.6 \\
\hline Single with children & 1.2 & 2.7 & 4.1 & 3.1 & 13.7 & 25.7 & 35.8 & 28.4 \\
\hline Couple with children & 19.5 & 20.6 & 22.4 & 18.1 & 28.7 & 30.0 & 26.0 & 14.6 \\
\hline Single & 51.5 & 51.3 & 56.8 & 54.2 & 51.4 & 51.0 & 59.4 & 56.7 \\
\hline Couple, both on IS & 21.4 & 25.2 & 29.4 & 41.8 & 21.6 & 25.7 & 28.0 & 40.9 \\
\hline Couple, one on IS & 27.1 & 23.5 & 13.8 & 4.0 & 27.0 & 23.3 & 12.6 & 2.3 \\
\hline No. of obs. & 8,264 & 6,000 & 2,927 & 1,769 & 7,253 & 5,919 & 3,933 & 2,899 \\
\hline
\end{tabular}

\section{Appendix C: One-year TTO measures by payment type - LDS}

Table C1: Proportion of individuals who at some stage in the year received each type of payment ${ }^{*}$

\begin{tabular}{rccccccc}
\hline \hline Year & $\begin{array}{c}\text { Unemployment } \\
\text { benefit }\end{array}$ & $\begin{array}{c}\text { Other } \\
\text { allowances }\end{array}$ & $\begin{array}{c}\text { Parenting } \\
\text { payment }\end{array}$ & $\begin{array}{c}\text { Sole parent } \\
\text { pension }\end{array}$ & Age pension & Other pension & $\begin{array}{c}\text { Number of } \\
\text { observations }\end{array}$ \\
\hline 1995 & 0.56 & 0.24 & 0.15 & 0.12 & 0.12 & 0.24 & 34,520 \\
1996 & 0.55 & 0.11 & 0.20 & 0.12 & 0.11 & 0.24 & 35,924 \\
1997 & 0.53 & 0.09 & 0.20 & 0.12 & 0.11 & 0.25 & 35,804 \\
1998 & 0.52 & 0.08 & 0.19 & 0.13 & 0.11 & 0.26 & 35,909 \\
1999 & 0.51 & 0.08 & 0.19 & 0.13 & 0.10 & 0.27 & 35,646 \\
\hline \hline
\end{tabular}

* The number of individuals who at some stage in the year were on the payment type as a proportion of all individuals who received IS payments in that year.

Table C2: One-year mean TTO by payment type*

\begin{tabular}{ccccccc}
\hline \hline Year & $\begin{array}{c}\text { Unemployment } \\
\text { benefit }\end{array}$ & $\begin{array}{c}\text { Other } \\
\text { allowances }\end{array}$ & $\begin{array}{c}\text { Parenting } \\
\text { payment }\end{array}$ & $\begin{array}{c}\text { Sole parent } \\
\text { pension }\end{array}$ & Age pension & Other pension \\
\hline 1995 & 0.55 & 0.43 & 0.36 & 0.75 & 0.89 & 0.88 \\
1996 & 0.56 & 0.57 & 0.62 & 0.77 & 0.87 & 0.89 \\
1997 & 0.58 & 0.59 & 0.62 & 0.78 & 0.92 & 0.89 \\
1998 & 0.59 & 0.62 & 0.65 & 0.74 & 0.88 & 0.89 \\
1999 & 0.57 & 0.64 & 0.64 & 0.77 & 0.91 & 0.89 \\
\hline \hline
\end{tabular}

* The mean proportion of time on the payment type for those people who at some stage in the year were on that payment type. 


\section{University Library}

\section{- M M I N E R VA A gateway to Melbourne's research publications}

Minerva Access is the Institutional Repository of The University of Melbourne

Author/s:

Tseng, Y-P;Wilkins, $R$

Title:

Reliance on income support in Australia: prevalence and persistence

Date:

2003

Citation:

Tseng, Y. -P. \& Wilkins, R. (2003). Reliance on income support in Australia: prevalence and persistence. Melbourne Institute of Applied Economic and Social Research.

Persistent Link:

http://hdl.handle.net/11343/33618 